\title{
OCRA radiometric cloud fractions for GOME-2 on MetOp-A/B
}

\author{
Ronny Lutz, Diego Loyola, Sebastián Gimeno García, and Fabian Romahn \\ German Aerospace Center (DLR), Remote Sensing Technology Institute (IMF), 82234 Weßling, Germany \\ Correspondence to: Ronny Lutz (ronny.lutz@dlr.de)
}

Received: 23 November 2015 - Published in Atmos. Meas. Tech. Discuss.: 18 December 2015

Revised: 29 April 2016 - Accepted: 3 May 2016 - Published: 30 May 2016

\begin{abstract}
This paper describes an approach for cloud parameter retrieval (radiometric cloud-fraction estimation) using the polarization measurements of the Global Ozone Monitoring Experiment-2 (GOME-2) onboard the MetOp-A/B satellites. The core component of the Optical Cloud Recognition Algorithm (OCRA) is the calculation of monthly cloud-free reflectances for a global grid (resolution of $0.2^{\circ}$ in longitude and $0.2^{\circ}$ in latitude) to derive radiometric cloud fractions. These cloud fractions will serve as a priori information for the retrieval of cloud-top height $(\mathrm{CTH})$, cloud-top pressure (CTP), cloud-top albedo (CTA) and cloud optical thickness (COT) with the Retrieval Of Cloud Information using Neural Networks (ROCINN) algorithm. This approach is already being implemented operationally for the GOME/ERS-2 and SCIAMACHY/ENVISAT sensors and here we present version 3.0 of the OCRA algorithm applied to the GOME-2 sensors.

Based on more than five years of GOME-2A data (April 2008 to June 2013), reflectances are calculated for $\approx 35000$ orbits. For each measurement a degradation correction as well as a viewing-angle-dependent and latitudedependent correction is applied. In addition, an empirical correction scheme is introduced in order to remove the effect of oceanic sun glint. A comparison of the GOME-2A/B OCRA cloud fractions with colocated AVHRR (Advanced Very High Resolution Radiometer) geometrical cloud fractions shows a general good agreement with a mean difference of $-0.15 \pm 0.20$.

From an operational point of view, an advantage of the OCRA algorithm is its very fast computational time and its straightforward transferability to similar sensors like OMI (Ozone Monitoring Instrument), TROPOMI (TROPOspheric Monitoring Instrument) on Sentinel 5 Precursor, as well as Sentinel 4 and Sentinel 5.
\end{abstract}

In conclusion, it is shown that a robust, accurate and fast radiometric cloud-fraction estimation for GOME-2 can be achieved with OCRA using polarization measurement devices (PMDs).

\section{Introduction}

The importance of clouds is not only manifested in the Earth's climate system due their significant influence on radiation processes, but also in the retrieval of atmospheric trace gases. Partially cloudy scenes may affect the retrieval of atmospheric species due to increased albedo, altered lower reflecting boundaries and modified photon path lengths. It is therefore necessary to accurately know the basic macrophysical cloud parameters (cloud fraction, cloud pressure, cloud height, cloud optical thickness) for providing reliable tracegas columns. In this paper, we report the retrieval of a radiometric cloud fraction from GOME-2 level-1b data using version 3.0 of the OCRA (Optical Cloud Recognition Algorithm).

The first Meteorological Operational satellite (MetOp-A), operated by the European Organisation for the Exploitation of Meteorological Satellites (EUMETSAT), was launched in October 2006 and follows a polar, sun-synchronous orbit with a descending node equatorial crossing time at 09:30 LST. It carries a GOME-2 instrument which is referred to as GOME-2A throughout this paper. Another GOME-2 instrument is also mounted on MetOp-B, which was launched in September 2012 and is referred to as GOME-2B in the following. The descending node equatorial crossing time of MetOp-B is also at 09:30 LST. In orbit, MetOp-A and MetOp-B are placed 48 min apart.

The GOME-2 heritage instrument GOME (Global Ozone Monitoring Experiment, see Burrows et al., 1999) onboard 
ERS-2 (European Remote Sensing 2 Satellite) also provided PMD (polarization measurement device) measurements. Further satellites also carrying passive nadir-viewing instruments suited for an OCRA-like cloud-fraction retrieval comprise OMI (Ozone Monitoring Instrument, see Levelt et al., 2006; Dobber et al., 2006; Schoeberl et al., 2006) on the NASA Aura Satellite, TROPOMI (TROPOspheric Monitoring Instrument, see Veefkind et al. (2012)) onboard the ESA Sentinel 5 Precursor mission as well as the Sentinel 4 and Sentinel 5 missions (Stark et al., 2013; Bézy et al., 2014).

Besides OCRA/ROCINN (Loyola, 1998, 2004), some other current cloud retrieval algorithms for UVN spectrometers are FRESCO+ (Wang et al., 2008), SACURA (Kokhanovsky et al., 2003) or HICRU (Grzegorski et al., 2006). The algorithms mentioned above all retrieve a radiometric or effective cloud fraction instead of a geometric one. The most significant difference between OCRA and the quoted algorithms on the other hand is the wavelength range in which the respective algorithm is operating. While OCRA uses broadband measurements (or measurements averaged over a very broad wavelength region) to determine the cloud fraction, much narrower wavelength bands are used by the other algorithms, e.g., the O2A-band for FRESCO+ and narrow bands around 382 or $519 \mathrm{~nm}$ for HICRU in the case of GOME-2 data.

In this paper we present the latest version 3.0 of the OCRA algorithm and the results obtained using GOME-2 data.

The basic idea of OCRA is to separate a scene into a contribution of clouds and a cloud-free background. In the context of the independent pixel approximation (IPA), the pixel reflectance can be expressed as the sum of the reflectances of the true cloudy part (i.e., geometrical cloud fraction) and the cloud-free part. Since these parts cannot be clearly separated given the PMD footprint resolution, OCRA computes a radiometric cloud fraction instead of a geometric one. The cloud-free background is calculated offline and provides reflectances in the absence of clouds for each month of the year for a global grid in a given resolution. For GOME-2, a global grid with a resolution of $0.2^{\circ}$ in both latitude and longitude was chosen. For each measured scene, OCRA takes the spectral information from the UV-VIS-NIR part and transforms the radiances of three predefined spectral ranges to three reflectances or RGB colors: R in the red part of the spectrum, $\mathrm{G}$ in the green part and B in the blue part. The cloud-free background maps are calculated for each of these three colors. OCRA further assumes that clouds have higher reflectivity than the surrounding underground and that clouds have a negligible spectral dependency in the regarded optical wavelength range, meaning that clouds appear white in the context of the RGB color scheme since all colors contribute the same amount. The radiometric cloud fraction is then finally determined by comparison of the measured reflectance of a given scene with its corresponding cloud-free reflectance from the cloud-free background. As shown in Van Roozendael et al. (2006), possible errors in the OCRA cloud fraction are com- pensated for in the ROCINN cloud-albedo retrieval resulting in a neglectable net effect on the trace-gas retrieval.

This paper is organized as follows: the data selection and preprocessing are found in Sect. 2. The latter includes reflectance corrections for several instrumental and noninstrumental effects. The methods specific to the OCRA algorithm are described in Sect. 3, which also contains the treatment of sun glint. The results are covered in Sect. 4 and include intercomparisons of OCRA for both GOME-2 instruments as well as comparisons with FRESCO and AVHRR cloud fractions. In the following, the OCRA performance over snow/ice conditions is discussed in Sect. 5. We finally close with the conclusions.

\section{Data selection and preprocessing}

The GOME-2 nadir-viewing optical spectrometer (Munro et al., 2016) senses Earth's backscattered radiance and solar irradiance at UV-VIS-NIR wavelengths in the range 240$790 \mathrm{~nm}$ at a spectral resolution between 0.2 and $0.4 \mathrm{~nm}$. In addition, GOME-2 also measures the state of linear polarization of the backscattered earthshine radiances in two perpendicular directions (parallel and perpendicular to the entrance slit) via the so-called polarization measurement devices (PMDs). The PMD data are taken at 15 spectral bands which cover the spectral region from 312 to $800 \mathrm{~nm}$. A nominal full GOME-2 swath has a width of $1920 \mathrm{~km}$ in the direction perpendicular to the flight direction and a single scan line has an extension of $40 \mathrm{~km}$ in the flight direction. A full GOME-2 scan consists of 256 PMD measurements (192 in the forward scan direction from east to west and 64 in the backscan from west to east). Since the backscan PMD pixels have a coarser spatial resolution compared to the forward scan pixels (due to different integration times), for the radiometric cloud retrieval with OCRA, only the PMD measurements of the forward scan are used. This results in 192 PMD pixels in the across-track direction, with each pixel having a footprint of $10 \mathrm{~km} \times 40 \mathrm{~km}$. Further information about GOME-2 can be found in the GOME-2 fact sheet (EUMETSAT, 2014).

All data considered in this section are from nominal $1920 \mathrm{~km}$ swath observations, excluding data in narrow swath mode or other modes like nadir static, PMD raw, calibration, etc. Our time base for GOME-2A data is 1 February 2007 to 30 September 2014 and for GOME-2B data it is 1 January 2013 to 30 September 2014. In order to construct the cloud-free background maps, we only use GOME-2A data from 1 April 2008 to 30 June 2013. The time before is excluded in this case because of another definition for the PMD bands which significantly affects the reflectance. Hence, for the cloud-free background maps, we only use data with PMD Def v3.1, which was uploaded to orbit on 12 March 2008, replacing the former PMD Def v1.0. An overview of the PMD band definitions v3.1 is given in Table 1. The time 
after 30 June 2013 is excluded, because the nominal swath for GOME-2A was changed from 1920 to $960 \mathrm{~km}$. From this time on, the tandem mode operation of both GOME-2 instruments was set to a $960 \mathrm{~km}$ swath for GOME-2A and a $1920 \mathrm{~km}$ swath for GOME-2B. This tandem-mode operation provides a gapless daily global coverage even at the equator. Other specific events occurring in the considered time frame are a key data update to the MetOp-A instrument model FM3 on 3 July 2012 as well as solar eclipses which might affect the data due to their ground shadow track. It is particularly important to avoid solar eclipses for the construction of the cloud-free composite maps because the abnormally low reflectance of a scene affected by the ground shadow track would falsely contribute to the maps. Therefore we discarded all orbits which might be affected by solar eclipses. A list of MetOp-A/B orbits which are affected by solar eclipses may be found in Appendix B of the Algorithm Theoretical Basis Document for the GOME-2 surface LER product (Tilstra et al., 2014b).

The following subsections provide a detailed description of the steps we applied in order to derive the cloud-free reflectance composites, beginning with the definition of colors which are mapped from the PMD reflectances and followed by various reflectance corrections. Afterwards, the basic concept of the OCRA algorithm is presented along with an empirical approach to identify scenes affected by sun glint and to correct the influence of those scenes on the cloud-fraction determination.

\subsection{Extraction of PMD reflectances}

In a first step, we determine the top-of-atmosphere (TOA) reflectance of each PMD measurement. The reflectance $\rho(\lambda)$ of a measurement at wavelength $\lambda$ is obtained.

$\rho=\frac{\pi \cdot I}{E_{0} \cdot \cos \Theta_{0}}$,

where $I(\lambda)$ denotes the upwelling radiance measured by the satellite, $E_{0}(\lambda)$ denotes the solar irradiance and $\Theta_{0}$ is the solar zenith angle (SZA). The wavelengths of the PMDs as defined for GOME-2 are listed in Table 1.

Since OCRA uses a RGB-color approach, we need to map the 15 PMD bands to the three colors R, G and B. Throughout this paper we define the color $\mathrm{B}$, or blue, as the mean of the reflectances of PMDs 2 to 6 (0-based), G, or green, as the mean of the reflectances of PMDs 7 to 10 (0-based) and R, or red, as the mean of the reflectances of PMDs 11 to 14 (see Table 2). This mapping is done for both possible polarization states: linear-parallel and linear-perpendicular polarization. For GOME-2, these two states are denoted by $\mathrm{P}$ and S. Hence, for each measurement, we denote the colors based on linear-parallel polarization as PB, PG and PR and those based on linear-perpendicular polarization as SB, SG and SR. The solar zenith angle in our reflectance determination is restricted to $<89^{\circ}$.
Table 1. GOME-2 PMD band definitions (v3.1). For GOME-2A, these settings have applied to the data since 11 March 2008. The PMD band definitions for GOME-2B differ slightly (mostly below one $\mathrm{nm}$ ) and can be found in the GOME-2 fact sheet (EUMETSAT, 2014).

\begin{tabular}{|c|c|c|c|c|c|}
\hline no. & \multicolumn{2}{|c|}{$\begin{array}{c}\text { Band-P } \\
\text { range in } \mathrm{nm}\end{array}$} & \multirow{2}{*}{$\begin{array}{r}\text { no. } \\
0\end{array}$} & \multicolumn{2}{|c|}{$\begin{array}{c}\text { Band-S } \\
\text { range in } \mathrm{nm}\end{array}$} \\
\hline 0 & 311.537 & 313.960 & & 311.709 & 314.207 \\
\hline 1 & 317.068 & 318.983 & 1 & 316.762 & 318.720 \\
\hline 2 & 321.603 & 329.267 & 2 & 321.389 & 329.139 \\
\hline 3 & 330.744 & 334.560 & 3 & 330.622 & 334.443 \\
\hline 4 & 336.157 & 340.302 & 4 & 336.037 & 340.161 \\
\hline 5 & 361.054 & 378.204 & 5 & 360.703 & 377.873 \\
\hline 6 & 380.502 & 384.049 & 6 & 380.186 & 383.753 \\
\hline 7 & 399.921 & 429.239 & 7 & 399.581 & 428.585 \\
\hline 8 & 434.779 & 492.569 & 8 & 434.083 & 492.066 \\
\hline 9 & 495.272 & 549.237 & 9 & 494.780 & 548.756 \\
\hline 10 & 552.967 & 556.769 & 10 & 552.474 & 556.262 \\
\hline 11 & 568.628 & 613.680 & 11 & 568.070 & 612.869 \\
\hline 12 & 618.711 & 662.990 & 12 & 617.867 & 661.893 \\
\hline 13 & 745.379 & 769.553 & 13 & 744.112 & 768.269 \\
\hline 14 & 795.364 & 804.351 & 14 & 794.080 & 803.072 \\
\hline
\end{tabular}

\subsection{Reflectance corrections and normalization}

Since instruments on a satellite happen to be in a very harsh environment, they cannot be perfectly stable and may therefore be subject to instrumental degradation. This instrumental degradation will, as a function of time, affect the measured reflectances; hence we need to correct for this effect.

Another aspect to be considered is a geometrical one: the mean reflectances for the swath edges will differ from those close to the nadir position of the swath. The same is true for different latitudinal positions, e.g., close to the equator or close to the poles. Finally, seasonal variations of the surface (predominantly variations of snow and ice cover) will have an impact on the measured mean reflectances. In the following, we account for these effects mentioned above by calculating correction factors for the reflectances as a function of time (and/or season), latitude and viewing zenith angle (VZA). VZA is used instead of the across-track PMD pixel position because the latter would lead to ambiguities when dealing with different swath widths (e.g., $1920 \mathrm{~km}$ vs. $960 \mathrm{~km}$ swaths).

The correction factors are based on statistically representative measurements which are assumed to describe a certain process well enough, e.g., global daily mean reflectances for degradation or monthly zonal mean reflectances for seasonal scan angle dependencies. For all corrections, the reference measurements are from 1 February 2007 for GOME-2A and 1 January 2013 for GOME-2B. We apply correction factors in two subsequent steps: the first step covers instrumental 
Table 2. OCRA definition of RGB-colors. The PMD numbers refer to the definitions given in Table 1.

\begin{tabular}{llll}
\hline & mean reflectance of PMD numbers & range in nm (Band-P) & range in nm (Band-S) \\
\hline OCRA color R & 11 to 14 & $568.628-804.351$ & $568.070-803.072$ \\
OCRA color G & 7 to 10 & $399.921-556.769$ & $399.581-556.262$ \\
OCRA color B & 2 to 6 & $321.603-384.049$ & $321.389-383.753$ \\
\hline
\end{tabular}
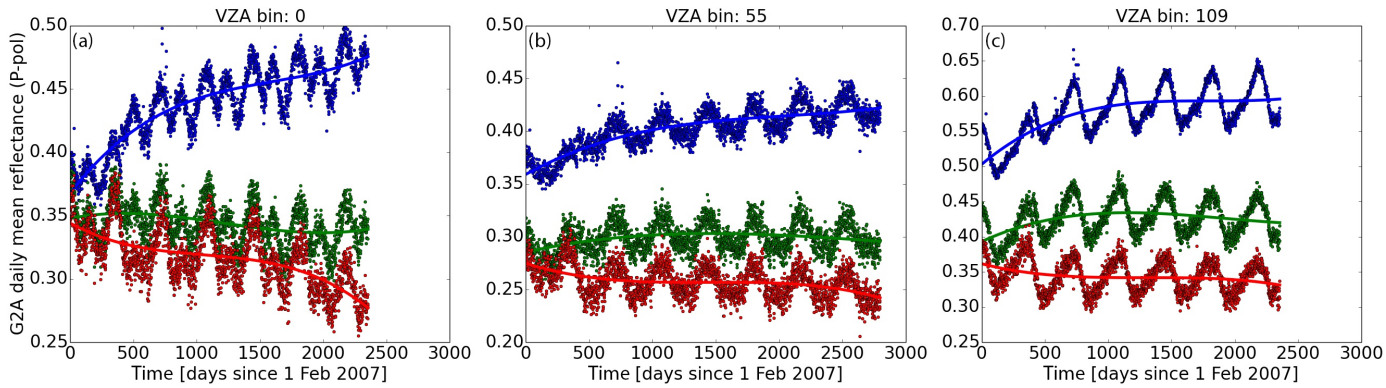

Figure 1. Instrumental degradation for GOME-2A as a function of time for the RGB OCRA colors. The examples shown here are only for P-pol data and for three VZA bins. (a) VZA bin 0: eastern swath edge at $-55^{\circ}$, (b) VZA bin 55: near-nadir center of swath and (c) VZA bin 109: western swath edge at $+55^{\circ}$. The solid lines are polynomial fits of third order and the time base is from 1 February 2007 to 30 September 2014.

degradation as a function of time and VZA and the second step covers geometrical aspects as a function of VZA, latitude and month (i.e., time). These two correction steps are outlined in the following two sections.

\subsubsection{Instrumental degradation}

Following the approach of Tilstra et al. (2012), we calculate a global daily mean reflectance for each of the 192 PMD pixels. In a subsequent step we map each PMD pixel to a VZA. The 192 PMD pixels are mapped to 110 viewing zenith angle bins of 1-degree width, which cover the region from $-55^{\circ}$ (eastern edge of swath) to $+55^{\circ}$ (western edge of swath) in VZA. Each global daily mean reflectance is comprised of all measurements within the latitude range from $60^{\circ} \mathrm{N}$ to $60^{\circ} \mathrm{S}$. For the whole data baseline, examples of the temporal evolution of the GOME-2A degradation are shown in Fig. 1 for the colors PB, PG and PR for three selected VZA bins: VZA bin 0 (eastern edge of swath, VZA $[-55,-50]$ degrees), VZA bin 55 (nadir part of swath, VZA [0, 5] degrees) and VZA bin 109 (western edge of the swath, VZA [50, 55] degrees).

Short-term periodic components in both cases are interpreted as variations due to seasonal changes, e.g., seasonal changes in snow and ice coverage, vegetation, foliage etc. (all resulting from the Earth's obliquity against the orbital plane). In contrast, the long-term component in both cases, GOME$2 \mathrm{~A}$ and GOME-2B, is attributed to instrumental degradation. For GOME-2A we chose a polynomial component of third degree and for GOME-2B a linear component (linear instead of third degree because the GOME-2B data only cover one and a half years and a third order polynomial would also fit the seasonal component. A more appropriate degradation model for GOME-2B will replace the linear model as soon as a sufficient temporal coverage of at least several annual cycles is reached).

We calculate degradation factors as a function of time and VZA by normalizing the polynomial (GOME-2A) or linear (GOME-2B) component to the reference measurements from 1 February 2007 for GOME-2A and 1 January 2013 for GOME-2B. Further, correction factors to be multiplied with the reflectances are calculated as the inverse of the degradation factors and stored in look-up tables (LUTs). Figures 1 and 2, respectively, show the instrumental degradation and degradation factors for GOME-2A. The same is presented for GOME-2B in Figs. 3 and 4. It is clear that the degradation of the reflectances does not follow a similar pattern but instead strongly depends on wavelength range (OCRA color) and viewing zenith angle. Also, depending on the degradation in the solar port compared to the Earth port, the degradation of the reflectance can be positive or negative.

Figures 5, 6 and 7 compare the instrumental degradation for GOME-2A and GOME-2B. Daily mean reflectances in the latitude range from $60^{\circ} \mathrm{N}$ to $60^{\circ} \mathrm{S}$ are plotted against time for the three OCRA colors PB (Fig. 5), PG (Fig. 6) and PR (Fig. 7) for the PMD pixels 0 (eastern edge of swath, panel a), 95 (near nadir, panel b) and 191 (western edge of swath, panel c). The reference measurement for GOME-2A is 1 February 2007 (MetOp-A orbit 1483) and for GOME-2B 1 January 2013 (MetOp-B orbit 1497), resulting in a similar in-orbit time at the reference points. The time difference between the two reference points for GOME-2A and GOME-2B is 2161 days. The colored dots represent GOME- 


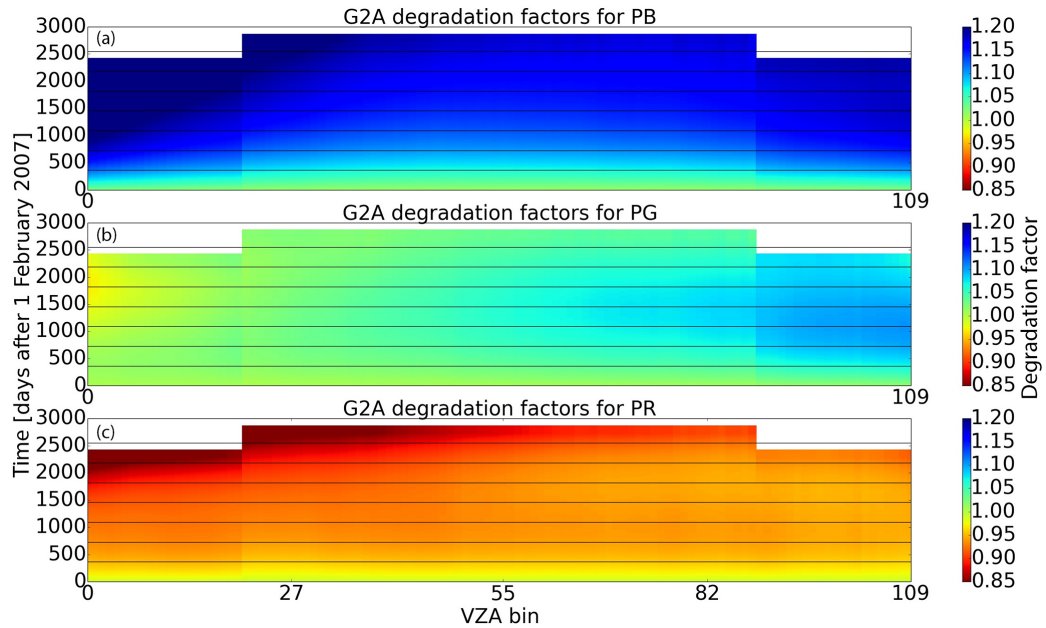

Figure 2. GOME-2A degradation factors as a function of time for the 110 across-track VZA bins for (a) color PB, (b) color PG and (c) color PR. The time runs in days starting on 1 February 2007 to 30 September 2014 in the positive y-axis direction. Yearly intervals are separated by horizontal solid lines. VZA bin 0 represents the eastern edge of the swath (VZA of -55 to $-50^{\circ}$ ), VZA bin 55 is close to nadir and VZA bin 109 represents the western edge of the swath (VZA of 50 to $55^{\circ}$ ). The VZA bins 0-20 and 89-109 are no longer occupied after the GOME-2A swath reduction from 1920 to $960 \mathrm{~km}$ in July 2013. This is seen as the white data gaps at the top of the panels. The calculation of the degradation factors is therefore based on two different data sets (February 2007 to July 2013 for VZA bins 0-20 and 89-109 and February 2007 to September 2014 for VZA bins 21-88), which leads to the slight discontinuity at the transition zones seen in the plot. Note that the color bar has the same scale in the three panels in order to allow a direct comparison of the three colors.
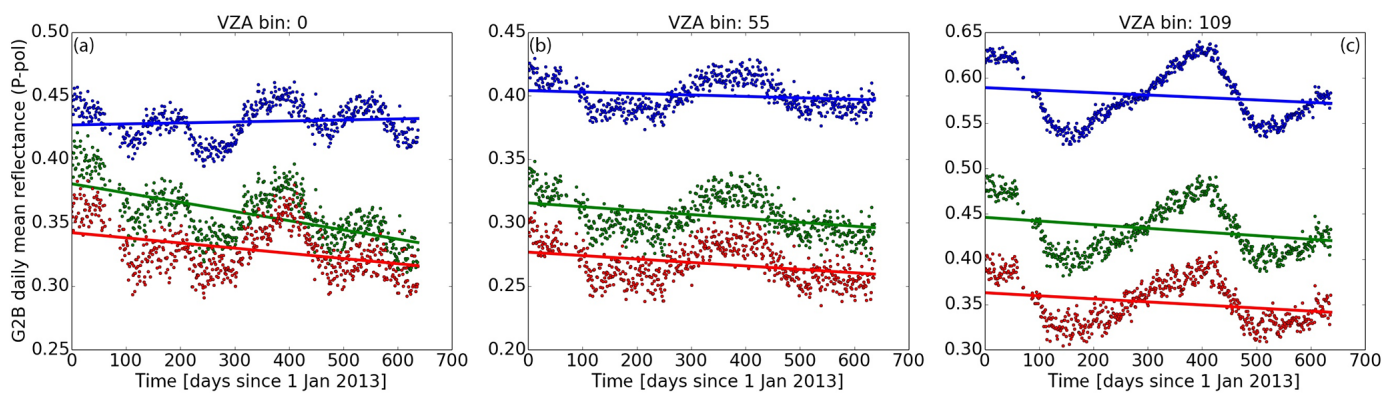

Figure 3. Instrumental degradation for GOME-2B as a function of time for the RGB OCRA colors. The examples shown here are only for P-pol data and for three VZA bins: (a) VZA bin 0: eastern swath edge at $-55^{\circ}$, (b) VZA bin 55: near-nadir center of swath and (c) VZA bin 109: western swath edge at $+55^{\circ}$. The solid lines are linear fits and the time base is from 1 January 2013 to 30 September 2014 .

2A data while the black dots represent GOME-2B data in the same timeline as GOME-2A, i.e., the GOME-2B timeline plus 2161 days. The grey circles represent GOME-2B data shifted such that they can be compared to the initial degradation of GOME-2A. The left dashed line marks the transition from PMD Def v1.0 to PMD Def v3.1 on 12 March 2008 for GOME-2A (which mainly affects $\mathrm{PB}$, but to a negligible extend $\mathrm{PG}$ and $\mathrm{PR}$ ) and the right dashed line represents the FM3 key data upgrade for MetOp-A on 3 July 2012, which does not seem to affect any of the colors.

The left hand sides of the figures allow us to estimate the effects of the PMD Definition version on the RGB reflectances. Left of the dashed line, PMD Def v1.0 was used for GOME-2A and right of the dashed line PMD Def v3.1 was applied to GOME-2A. The effect is significant for PB, while they are minor for PG and PR. Also, the GOME-2B reflectances, shifted to match the in-orbit time of GOME$2 \mathrm{~A}$, align very well with the GOME-2A reflectances after 12 March 2008. This is because the PMD Definitions for GOME-2B are very close to the PMD Def v3.1 of GOME2A.

The right hand side of the figures allows for an estimation of the effect of degradation and demonstrates that it is nontrivial, and they depend not only on time but also on wavelength range (here colors $\mathrm{PB}, \mathrm{PG}$ or PR) and viewing zenith angle (here PMD pixels 0, 95 and 191). It is further noted that PG and PR show a positive degradation for all three cases (east, nadir and west), meaning that the measured reflectances decreased over time. In contrast, PB shows a negative degradation associated with an increase of the reflectance 


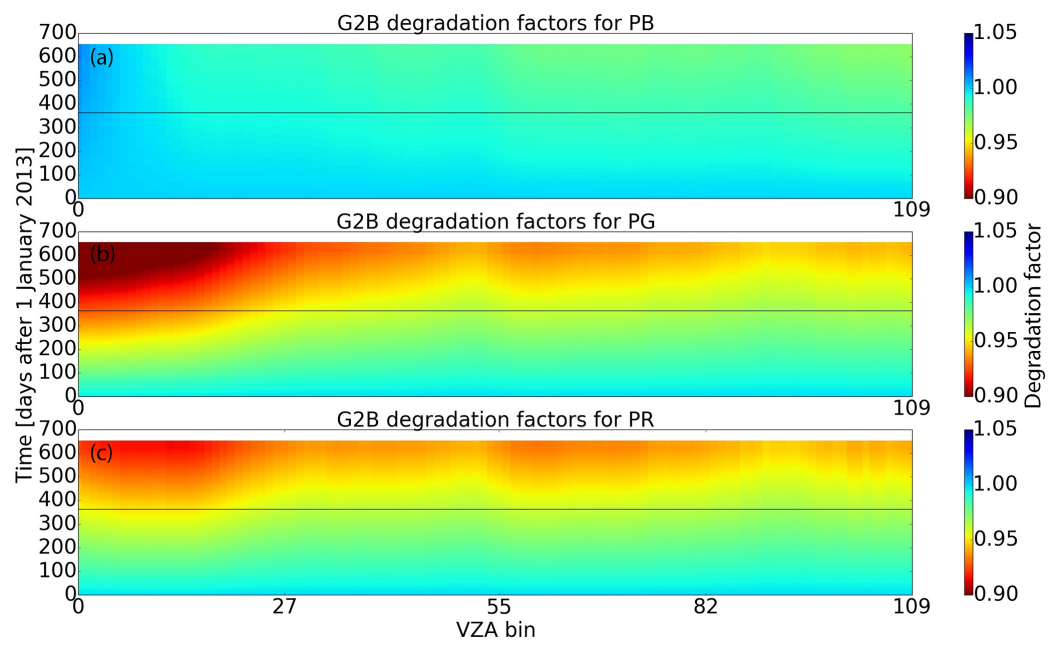

Figure 4. GOME-2B degradation factors as a function of time for the 110 across-track VZA bins for (a) color PB, (b) color PG and (c) color PR. The time runs in days starting on 1 January 2013 and ending on 30 September 2014 in the positive $y$ axis direction. Yearly intervals are separated by horizontal solid lines. VZA bin 0 represents the eastern edge of the swath (VZA of -55 to $-50^{\circ}$ ), VZA bin 55 is close to nadir and VZA bin 109 represents the western edge of the swath (VZA of 50 to $55^{\circ}$ ). Note that the color bar has the same scale in the three panels in order to allow a direct comparison of the three colors.

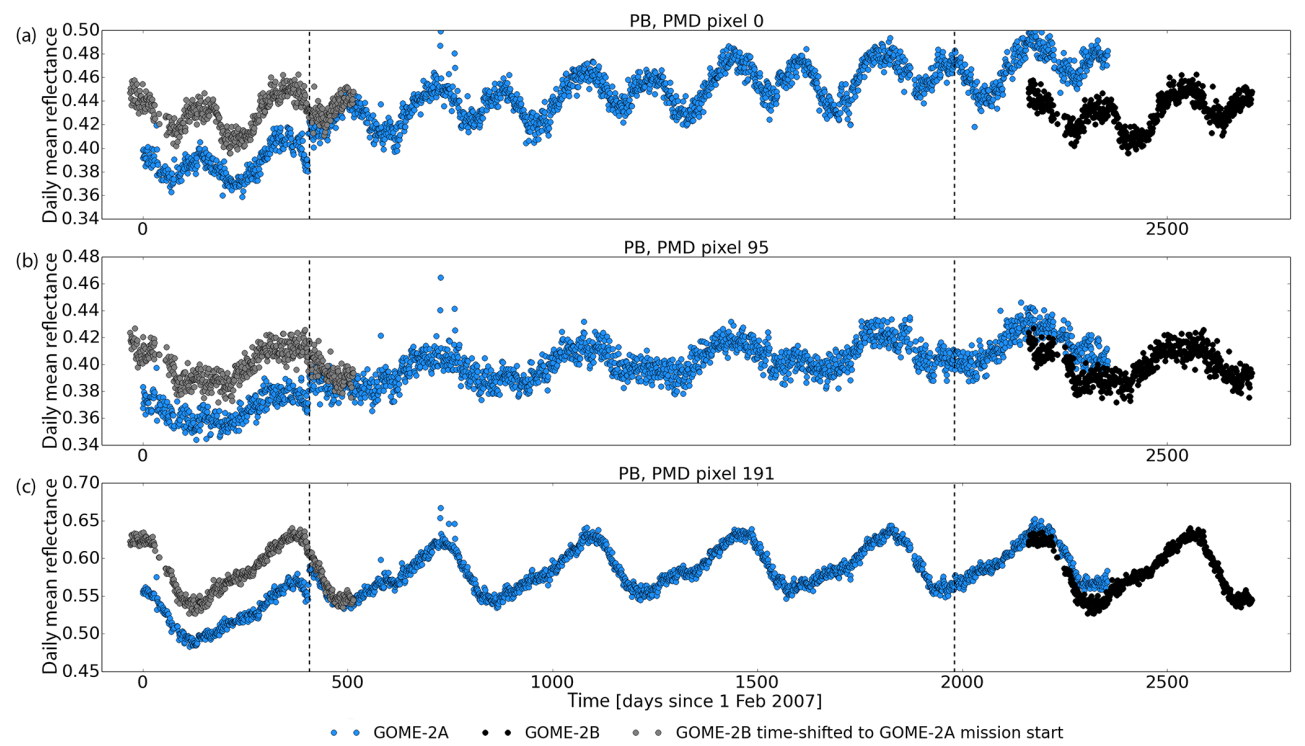

Figure 5. Comparison of degradation for GOME-2A and GOME-2B for color PB. Panel (a) shows the PMD pixel 0 at the eastern swath edge, (b) shows PMD pixel 95 near nadir and (c) shows PMD pixel 191 at the western swath edge. Blue dots represent GOME-2A data, black dots represent GOME-2B data and grey dots represent GOME-2B data time-shifted such that it can be compared to the in-orbit time of GOME-2A.

over time. A common feature for all three colors is that the degradation (positive or negative) is strongest at the eastern swath edge (pixel 0) and weakest at the western swath edge (pixel 191). The sign of the degradation of the reflectance is also influenced by the degradation of the solar port. We presume that a negative degradation in the reflectance (as seen for PB) may be associated with a faster positive degradation of the solar channel compared to the Earth channel.

\subsubsection{Dependencies on viewing angles, latitudes and seasons}

After the correction for the instrumental degradation, we calculated monthly mean reflectances for each PMD pixel (or VZA bin). The monthly mean reflectance depends not only on the viewing angle (PMD pixel) but also on the latitude (see Figs. 8 and 9 for GOME-2A and GOME-2B, respectively). We consider a total of 14 latitude bands. Twelve 

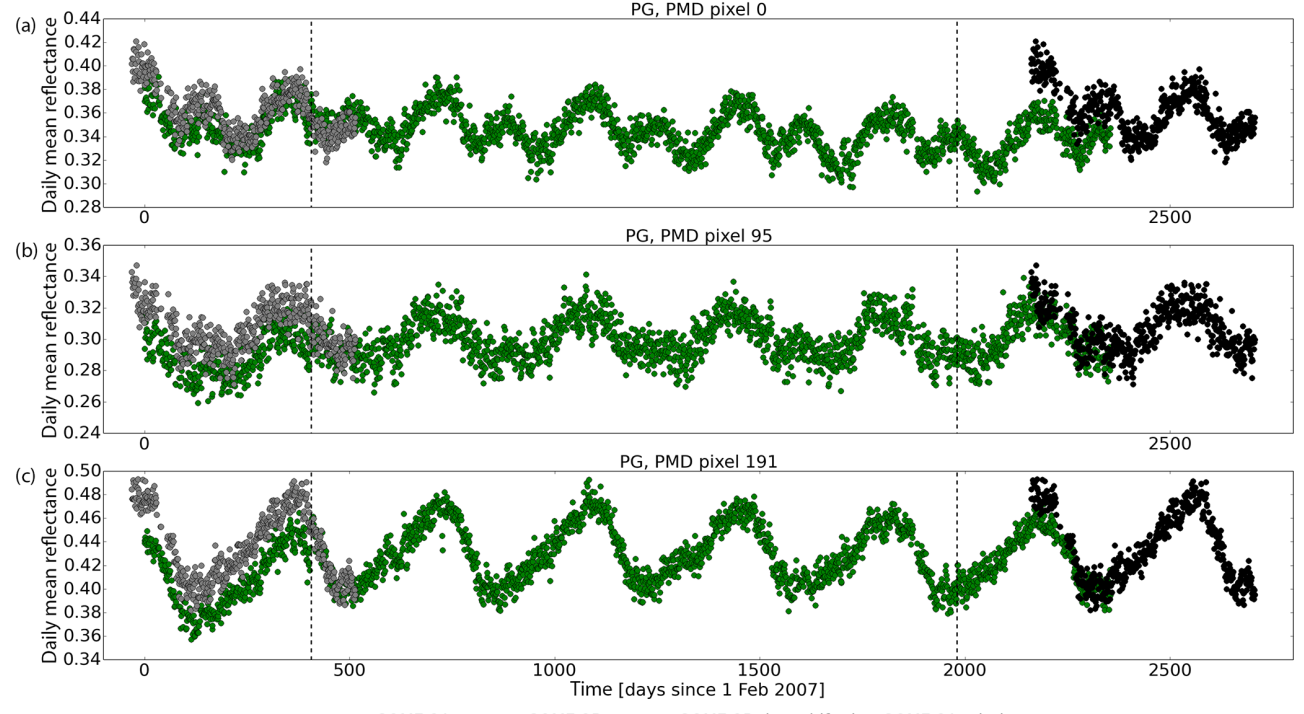

Figure 6. Comparison of degradation for GOME-2A and GOME-2B for color PG. Panel (a) shows the PMD pixel 0 at the eastern swath edge, (b) shows PMD pixel 95 near nadir and (c) shows PMD pixel 191 at the western swath edge. Green dots represent GOME-2A data, black dots represent GOME-2B data and grey dots represent GOME-2B data time-shifted such that it can be compared to the in-orbit time of GOME-2A.
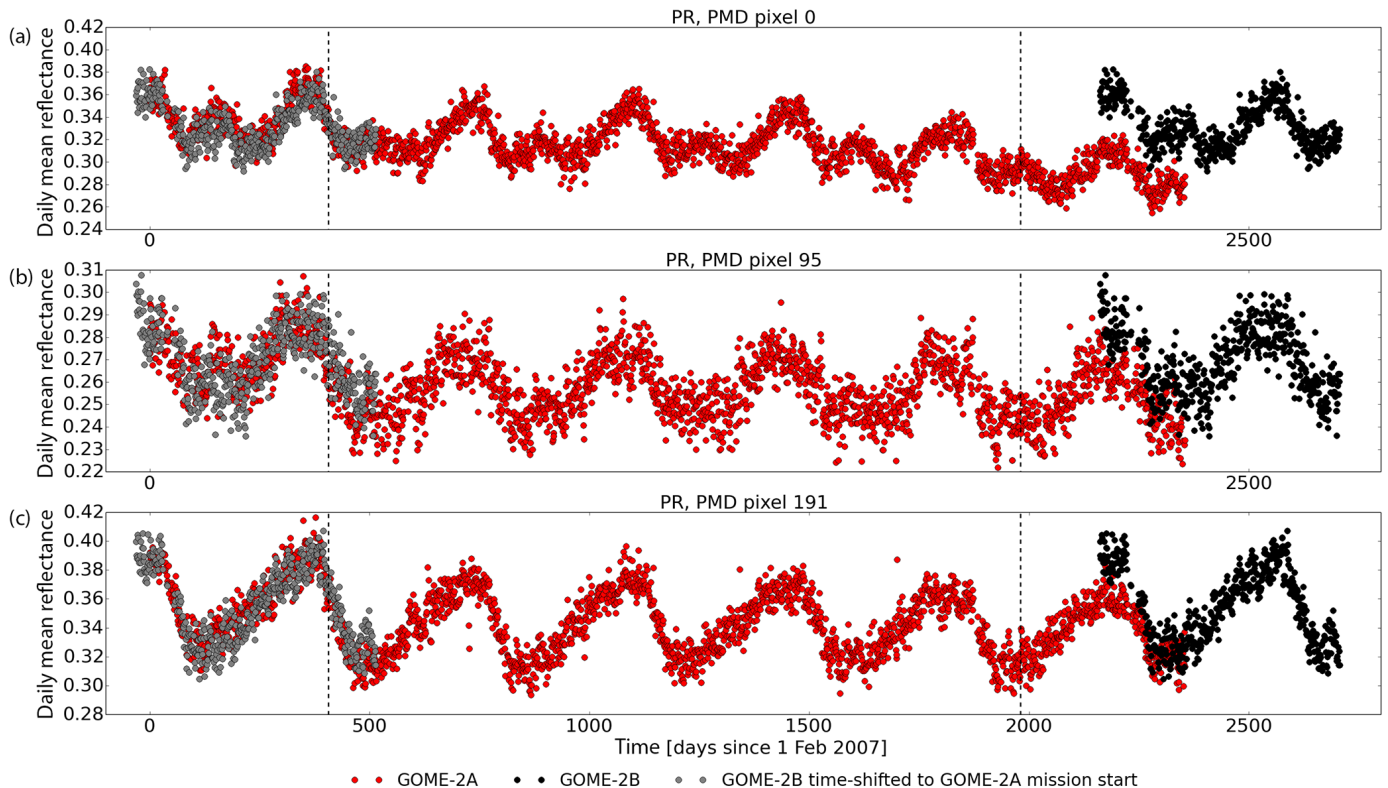

Figure 7. Comparison of degradation for GOME-2A and GOME-2B for color PR. Panel (a) shows the PMD pixel 0 at the eastern swath edge, (b) shows PMD pixel 95 near nadir and (c) shows PMD pixel 191 at the western swath edge. Red dots represent GOME-2A data, black dots represent GOME-2B data and grey dots represent GOME-2B data time-shifted such that it can be compared to the in-orbit time of GOME-2A.

bands with a width of $10^{\circ}$ between $[-60,+60]$ and two bands with a width of $30^{\circ}$ for latitudes $>60$ and $<-60$ (i.e., towards the poles). To estimate the effect of the viewing angle and the latitude on the measured mean reflectance and to correct for it, we do the following procedure for each month considered. For each PMD pixel $x$ the mean reflectance of every latitude band $\bar{\varphi}$ is calculated for a whole month of data and fitted with a fourth order polynomial:

$$
\rho_{\text {mean }}(x, \bar{\varphi})=\alpha_{x, \bar{\varphi}}+\beta_{x, \bar{\varphi}} \cdot x+\gamma_{x, \bar{\varphi}} \cdot x^{2}+\delta_{x, \bar{\varphi}} \cdot x^{3}+\epsilon_{x, \bar{\varphi}} \cdot x^{4},
$$

where $\alpha_{x, \bar{\varphi}}, \beta_{x, \bar{\varphi}}, \gamma_{x, \bar{\varphi}}, \delta_{x, \bar{\varphi}}$ and $\epsilon_{x, \bar{\varphi}}$ are the fit parameters for the corresponding pixel $x$ (PMD pixels from 0 to 191) 

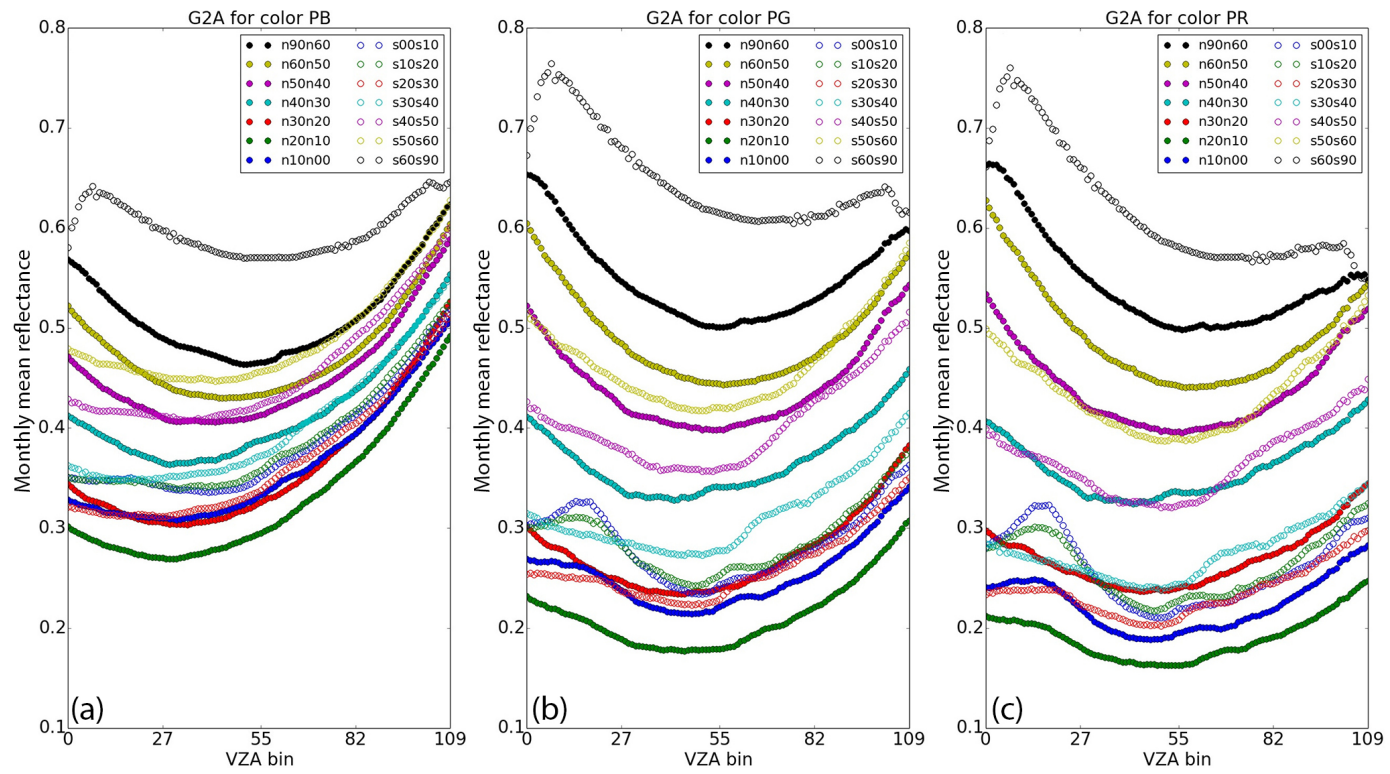

Figure 8. GOME-2A monthly mean reflectances for (a) OCRA color PB, (b) OCRA color PG and (c) OCRA color PR in February 2007 in 14 latitude bands. The bands have a bin size of $10^{\circ}$ in the latitude range from $60^{\circ} \mathrm{N}$ to $60^{\circ} \mathrm{S}$ and a bin size of $30^{\circ}$ for the polar regions [60, $90 \mathrm{~N}]$ and $\left[60,90^{\circ} \mathrm{S}\right]$. The filled circles represent the northern hemisphere and the open circles represent the southern hemisphere.
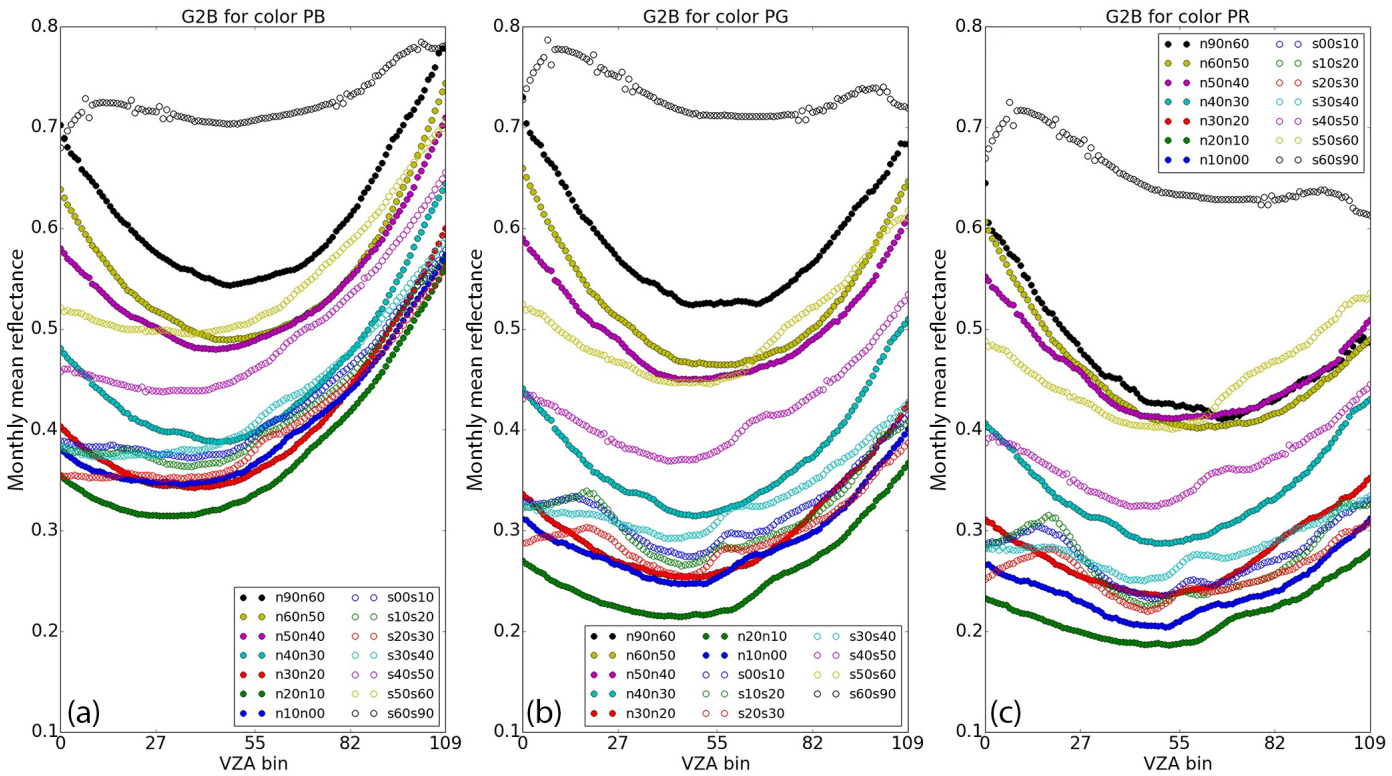

Figure 9. Same as Fig. 8, but for GOME-2B and January 2013.

and latitude band $\bar{\varphi}$. The correction factor $c(x, \bar{\varphi})$ for the reflectance measurement at pixel $x$ and latitude band $\bar{\varphi}$ is calculated by normalization to the mean reflectance of the closeto-nadir pixel (PMD pixel 95 of 191) of the corresponding latitude band:

$c(x, \bar{\varphi})=\frac{\rho_{\text {mean }}(x, \bar{\varphi})}{\rho_{\text {mean }}(95, \bar{\varphi})}$.
To get the correction factor $c(x, \varphi)$ for an arbitrary latitude $\varphi$, we apply a linear interpolation between the correction factors $c(x, \bar{\varphi})$ of the 14 latitude bands $\bar{\varphi}$ for each of the across-track PMD pixels $x$. If the VZA is used instead of the across-track PMD pixel position, the $x$ in Eqs. (2) and (3) has to be replaced by the VZA and the nadir pixel 95 in the denominator of Eq. (3) has to be replaced by the VZA bin 55 which is the VZA bin closest to nadir. 

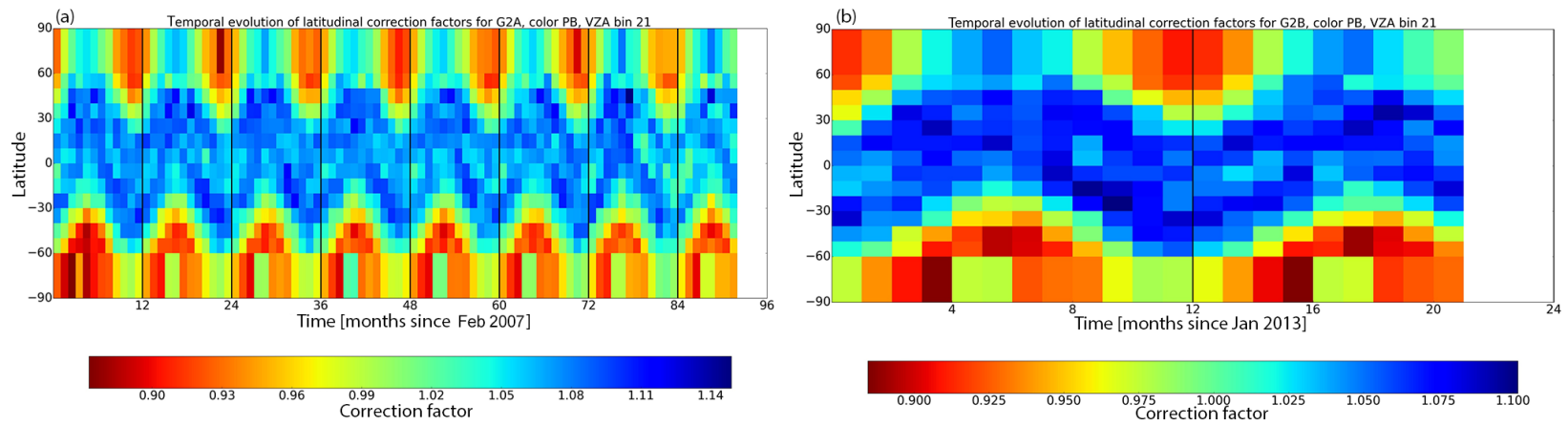

Figure 10. Temporal evolution of correction factors for scan angle and latitudinal dependencies for (a) GOME-2A and (b) GOME-2B. The example is for color PB and VZA bin 21, which corresponds to viewing zenith angles in the range [-34, -33] degrees. The times are given in years from February 2007 and January 2013 for the respective panels and the vertical black lines separate yearly intervals.

For each month considered, the fitting parameters for calculating the pixel- and latitude-dependent correction values for all OCRA colors and polarizations are then stored in LUTs. The same is done in the case of the VZA- and latitudedependent correction values. The viewing angle and latitudinal dependencies for GOME-2A are shown for the example of the month of February 2007 for the P-pol data in Fig. 8 and for GOME-2B for the month of January 2013 in Fig. 9. The general shape is very similar in all other months. As can be seen as a general feature, the monthly mean reflectances are larger at the swath edges than at the nadir position for all three colors or more generally at the central part of the swath. Similarly, the monthly mean reflectances are larger in polar and subpolar latitudes and smaller in tropical latitudes. Also the curvature is slightly different in different months throughout the year. It is stronger in winter months and weaker in summer months (not shown here).

Similarly to the degradation correction, the correction factors for the dependencies on viewing angles, latitudes and seasons are also stored in LUTs for all combinations of colors and polarization state. See Fig. 10 for the temporal evolution of the correction factors for viewing angle and latitudinal dependencies for GOME-2A (February 2007 to September 2014) and GOME-2B (January 2013 to September 2014), respectively. The annual periodicity is clearly visible.

\section{Methods}

As outlined in the introduction, the basic idea of OCRA is to separate a scene into a contribution of clouds and a cloudfree background. The following subsections explain in detail the initial step of generating the cloud-free reflectance background, the cloud-fraction determination with OCRA and finally an improved approach for the removal of sun glint.

\subsection{Construction of cloud-free reflectance composites}

After correcting the reflectances for instrumental degradation and dependencies on viewing angles, latitudes and seasons, we apply the following color approach to determine cloudfree reflectance composite maps.

First, a grid with a resolution of $0.2^{\circ}$ in latitude and longitude is defined (globally resulting in $900 \times 1800=1620000$ grid cells). For each grid cell we collect all GOME-2A measurements between April 2008 and June 2013 (63 months) with central longitude and latitude within the borders of each grid cell. Since we want to derive monthly cloud-free composites, these measurements are further divided according to the month in which they were taken (the same months in consecutive years are combined). Based on the 5-year data set, the resulting number of measurements per grid cell and per month is around 120 to 180 , depending on geolocation. Grid cells closer to the poles have a shorter revisit timescale and will therefore likely contain more measurements within a given time frame than a grid cell at the equator. For each color (PB, PG and PR) the normalized color $(\mathrm{Pb}, \mathrm{Pg}$ and $\mathrm{Pr})$ is obtained.

$$
\begin{aligned}
\mathrm{Pb} & =\frac{\mathrm{PB}}{\mathrm{PB}+\mathrm{PG}+\mathrm{PR}} \\
\mathrm{Pg} & =\frac{\mathrm{PG}}{\mathrm{PB}+\mathrm{PG}+\mathrm{PR}} \\
\mathrm{Pr} & =\frac{\mathrm{PR}}{\mathrm{PB}+\mathrm{PG}+\mathrm{PR}}
\end{aligned}
$$

The normalized colors based on S-polarization $(\mathrm{Sb}, \mathrm{Sg}$ and $\mathrm{Sr}$ ) are obtained in a similar way. In contrast to the nonnormalized RGB colors (which are reflectances), the normalized colors rgb add up to unity, i.e., $r+g+b=1$. In a $\mathrm{Pr}-\mathrm{Pg}$ or $\mathrm{Sr}-\mathrm{Sg}$ color diagram, let $w=(1 / 3,1 / 3)$ be the white point and $M_{\mathrm{P}}=(\mathrm{Pr}, \mathrm{Pg})$ and $M_{\mathrm{S}}=(\mathrm{Sr}, \mathrm{Sg})$ be the measurements based on P-polarization and S-polarization, respectively. Then the distances $d_{\mathrm{P}}$ and $d_{\mathrm{S}}$ from the measurement 

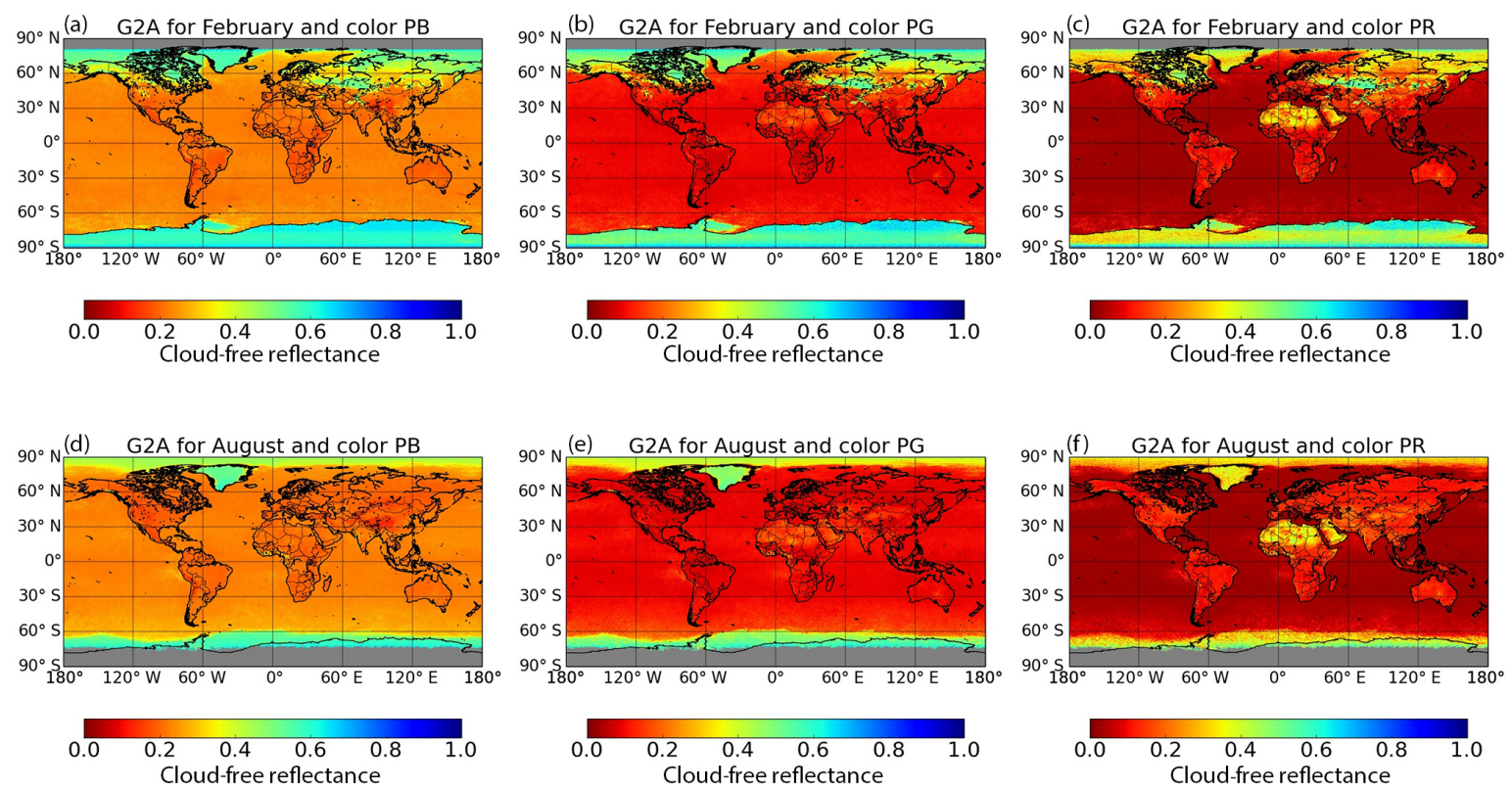

Figure 11. GOME-2A cloud-free background maps for (a) color PB in February, (b) color PG in February, (c) color PR in February, (d) color PB in August, (e) color PG in August and (f) color PR in August.

to the white point for the two polarization cases are given.

$$
\begin{aligned}
& d_{\mathrm{P}}=\sqrt{\left(\operatorname{Pr}-\frac{1}{3}\right)^{2}+\left(\operatorname{Pg}-\frac{1}{3}\right)^{2}}, \\
& d_{\mathrm{S}}=\sqrt{\left(\mathrm{Sr}-\frac{1}{3}\right)^{2}+\left(\operatorname{Sg}-\frac{1}{3}\right)^{2}}
\end{aligned}
$$

The distances from the white point are calculated for all measurements within a grid cell and the RGB colors of the measurement with the largest distance from the white point are defined to represent the cloud-free situation of that grid cell. By merging the cloud-free conditions of all grid cells, we can finally obtain global cloud-free TOA reflectance composite maps for each month and RGB color. All cloud-free composite maps are stored in look-up tables. Some examples for the spring and summer months for OCRA colors PB, PG and PR are shown in Fig. 11. Close to the poles it may occur that cells do not contain enough data. Such cells are assigned with $\mathrm{NaN}$ values and appear grey in the plots. It may be noted here that the cloud-free reflectance for PR in February appears to be below 0.5 for some geolocations over Antarctica, see Fig. 11c). A study by Casacchia et al. (2002) concludes that the snow/ice reflectance significantly depends on various characteristics (e.g., grain size, impurities, water content, surface roughness, snow age) and that large grain sizes, high water content and soot/dust impurities can in fact effectively decrease the reflectance in the visible spectral range associated with the OCRA PR color, i.e., around 600-800 nm, to values well below 0.5 . We assume the low reflectances at some Antarctic geolocations to be associated to such effects outlined above.

Since a proper construction of the cloud-free composites requires a large amount of data and especially the largest possible temporal coverage, we use GOME-2A for creating the cloud-free maps. The current GOME-2B data record is still well below three years and simply too short to achieve enough measurements per grid cell to derive stable cloudfree values at the given grid cell resolution of 0.2 by $0.2^{\circ}$. Once the mission lifetime of GOME-2B is above four to five years, we will create cloud-free composites based on the GOME-2B data themselves to derive the GOME-2B OCRA cloud fractions. Until then, the GOME-2A maps will be used for GOME-2B too. Figure 12 shows rg-diagrams of the yearly temporal evolution of the cloud-free conditions for six different surface types. It can be nicely seen that the normalized color of the cloud-free background does not change significantly for the Amazon rainforest, South Atlantic Ocean and Sahara cases throughout the course of the year. In contrast, the Vancouver, Alps and Hudson Bay cases show significant monthly changes of the cloud-free background during the melting season (April-May-June) and the beginning of winter with fresh snow (October-November-December). Also, fresh snow seems to have lower Pr values (November, December) compared to old snow (March).

\subsection{Cloud-fraction determination}

The determination of the radiometric cloud fraction with OCRA follows a two-step process. The first part consists of the separation of a scene into a contribution from the 

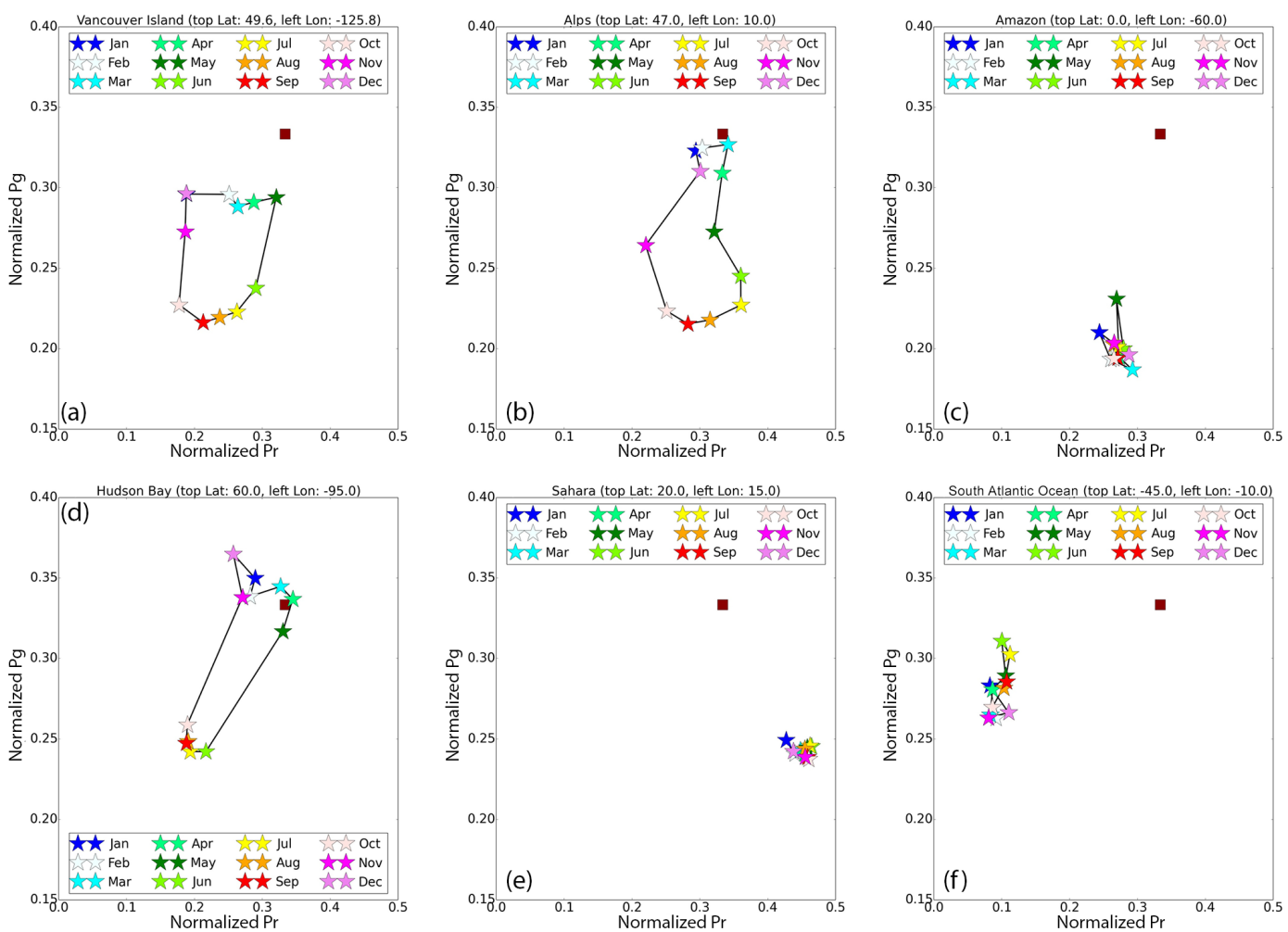

Figure 12. Yearly evolution of cloud-free reflectances in a normalized rg-color-diagram for different surface types: (a) Vancouver Island, (b) Alps, (c) Amazon rainforest, (d) Hudson Bay, (e) Sahara and (f) South Atlantic Ocean. The square symbol marks the white point of the normalized color diagram. The cloud-free scenes in subsequent months are connected with solid black lines.

clouds and a cloud-free background and has been described in Sect. 3.1. The second part involves a comparison of the measured reflectance of a scene with its corresponding cloudfree situation. This second step is now outlined in the rest of this subsection.

\subsubsection{Matching the measurements to the cloud-free grid}

In order to find the corresponding cloud-free reflectance for a measured scene, we search for the grid cell of the composite map which contains the central latitude and longitude of the measured pixel. The final cloud-free value is determined via linear interpolation between the two monthly cloud-free composite maps enclosing the observation. We assume a monthly cloud-free map to correspond to the middle of the month. If a measurement is dated in the first half of a month, we find the cloud-free value via linear interpolation between the cloud-free maps of the previous and current month and if the measurement is dated in the second part of a month, we obtain the cloud-free value via linear interpolation between the cloud-free maps of the current and next month.

\subsubsection{OCRA}

OCRA determines the cloud fraction using the differences between the colors of a measured scene and its corresponding cloud-free values. Let $\lambda_{i}$, with $i=\mathrm{R}, \mathrm{G}, \mathrm{B}$, be the wavelength ranges of the OCRA colors as defined in Table 2. Furthermore, let $\rho\left(\lambda_{i}\right)$ be the measured reflectances and $\rho_{\mathrm{CF}}\left(\lambda_{i}\right)$ the cloud-free background values of the grid cell corresponding to the geolocation of the measured reflectances. The radiometric cloud fraction $f_{\mathrm{c}}$ is then obtained by the following equation.

$$
\begin{aligned}
f_{\mathrm{c}} & =\min \{1, \\
& \left.\sqrt{\sum_{i=\mathrm{R}, \mathrm{G}, \mathrm{B}} \alpha\left(\lambda_{i}\right) \cdot \max \left\{0, \rho\left(\lambda_{i}\right)-\rho_{\mathrm{CF}}\left(\lambda_{i}\right)-\beta\left(\lambda_{i}\right)\right\}^{2}}\right\},
\end{aligned}
$$

where the scaling factors $\alpha\left(\lambda_{i}\right)$ are determined by a histogram analysis of the difference $\rho\left(\lambda_{i}\right)-\rho_{\mathrm{CF}}\left(\lambda_{i}\right)$ at a cumulative histogram value of 0.99 .

$\alpha\left(\lambda_{i}\right)=\frac{1}{\left(\rho\left(\lambda_{i}\right)-\rho_{\mathrm{CF}}\left(\lambda_{i}\right)\right)_{0.99}^{2}}$

The offset values $\beta\left(\lambda_{i}\right)$ are determined by a histogram analysis of the difference $\rho\left(\lambda_{i}\right)-\rho_{\mathrm{CF}}\left(\lambda_{i}\right)$ at the mode of the nor- 

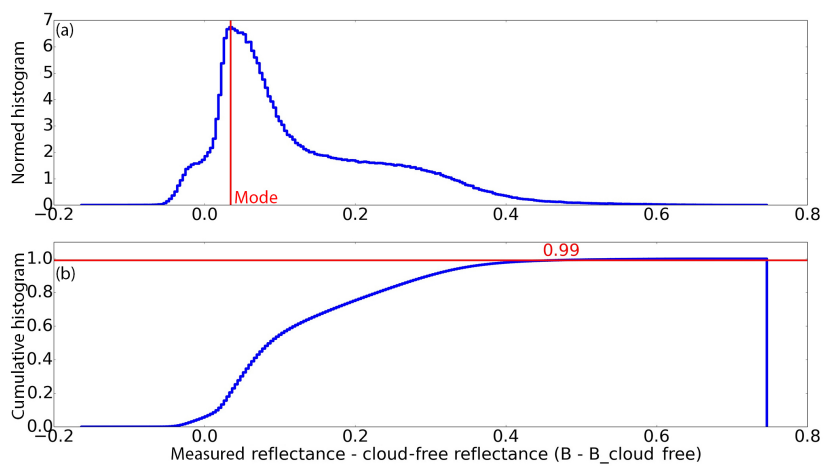

Figure 13. Determination of $\alpha$ and $\beta$ via histogram analysis of the differences between the measured reflectance and the cloud-free reflectance. This example shows GOME-2A data from 1 February 2007 for color B: (a) $\beta$ is determined via the mode of the normalized histogram, (b) $\alpha$ is determined via the reflectance difference at the 0.99 value of the cumulative histogram.

mal histogram.

$\beta\left(\lambda_{i}\right)=\left(\rho\left(\lambda_{i}\right)-\rho_{\mathrm{CF}}\left(\lambda_{i}\right)\right)_{\text {mode }}$

These parameters $\alpha$ and $\beta$ practically act as upper and lower thresholds defining a fully clouded and a cloud-free scene, respectively. They can also compensate for exceptionally bright situations (e.g., extreme sun glint) and for exceptionally dark situations (e.g., shadowing effects, darkening due to aerosols). The $\max (0, x)$ and $\min (1, x)$ functions in the equation above ensure a mapping of the cloud fractions to the interval $[0,1]$.

The cloud-fraction determination is done separately for the P-based colors (PB, PG, PR) and S-based colors (SB, SG, $\mathrm{SR}$ ) and the final cloud fraction is taken as the mean of the $\mathrm{P}$ - and S-based cloud fractions.

For GOME-2A the scaling factors $\alpha$ and offset values $\beta$ are determined from 29 test days spread over a 6-year period. Each test day uses the same criteria: the scaling factor $\alpha$ via the 0.99 cumulative histogram value of the difference $\rho\left(\lambda_{i}\right)-\rho_{\mathrm{CF}}\left(\lambda_{i}\right)$ and the offset value $\beta$ via the mode of the normalized histogram value of $\rho\left(\lambda_{i}\right)-\rho_{\mathrm{CF}}\left(\lambda_{i}\right)$. See Fig. 13 for an example. Over the 6-year time base, there is no significant trend or variation seen in the parameters of the 29 test days; hence we can use one fixed set of alphas and betas for the whole mission (see Table 3). For GOME-2B we use 6 test days spread over a time period of 18 months to determine the scaling factors and offset values.

An example of a normalized rg-color diagram for a grid cell near Munich for the month of April is shown in Fig. 14 and contains 128 measurements which happened to be in this grid cell in the month of April during the years 2007-2013. It is obvious that the strong variation of the cloud-free condition from one month to the other (big star symbols in the plot) call for an interpolation towards daily cloud-free values (small star symbols in the plot).
Table 3. OCRA scaling factors and offset values for GOME-2A and GOME-2B.

\begin{tabular}{rcrrrrrr}
\hline & & \multicolumn{2}{c}{ P-polarization } & & \multicolumn{2}{c}{ S-polarization } \\
\cline { 3 - 4 } \cline { 7 - 8 } & Color & $\alpha$ & $\beta$ & & $\alpha$ & $\beta$ \\
\hline \multirow{3}{*}{ GOME-2A } & $\mathrm{B}$ & 4.7 & 0.033 & & 4.8 & 0.033 \\
& $\mathrm{G}$ & 2.6 & 0.035 & & 2.6 & 0.035 \\
& $\mathrm{R}$ & 2.1 & 0.020 & & 2.1 & 0.020 \\
\hline \multirow{3}{*}{ GOME-2B } & $\mathrm{B}$ & 3.15 & 0.048 & & 3.35 & 0.047 \\
& $\mathrm{G}$ & 2.10 & 0.039 & & 2.25 & 0.032 \\
& $\mathrm{R}$ & 2.00 & 0.014 & & 1.85 & 0.019 \\
\hline
\end{tabular}

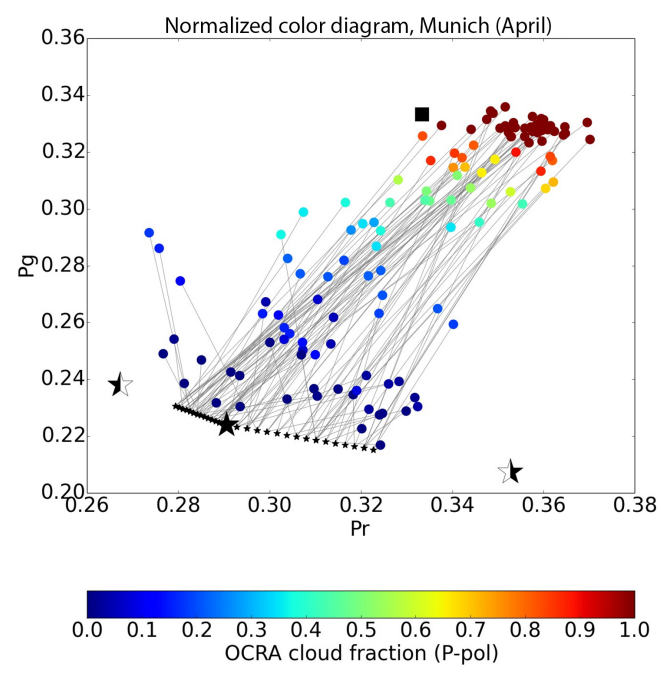

Figure 14. Normalized rg-color-diagram for an example $0.2 \times 0.2$ grid cell (Munich, Latitude [48.0, 48.2], Longitude [11.6, 11.8]). This diagram contains all measurements from April for the years 2007-2013. The black square marks the white point at $(1 / 3,1 / 3)$. The big stars represent the monthly cloud-free conditions for March (left filled star), April (filled star) and May (right filled star) taken from the LUT. The small stars represent daily cloud-free conditions for the month of April, found by linear interpolation between the three LUT values for March, April and May. Each measurement is color-coded with its resulting OCRA cloud fraction and connected to its corresponding interpolated daily cloud-free condition via a thin grey line.

\subsection{Sun glint removal}

Under certain geometrical conditions, sunlight reflected by the ocean surface may directly reach the satellite sensor enhancing the measured signal in comparison to a nonaffected scene over water. This effect is called sun glint. More details on this effect may be found in Kay et al. (2009, 2013) and applications to spaceborne sensors are outlined in Zhang and Wang (2010), Hu (2011) and Steinmetz et al. (2011). Since clouds in the visual appear bright, the sun glint will affect the OCRA cloud-fraction retrieval by mimicking an enhanced cloud fraction. The flagging of measurements 


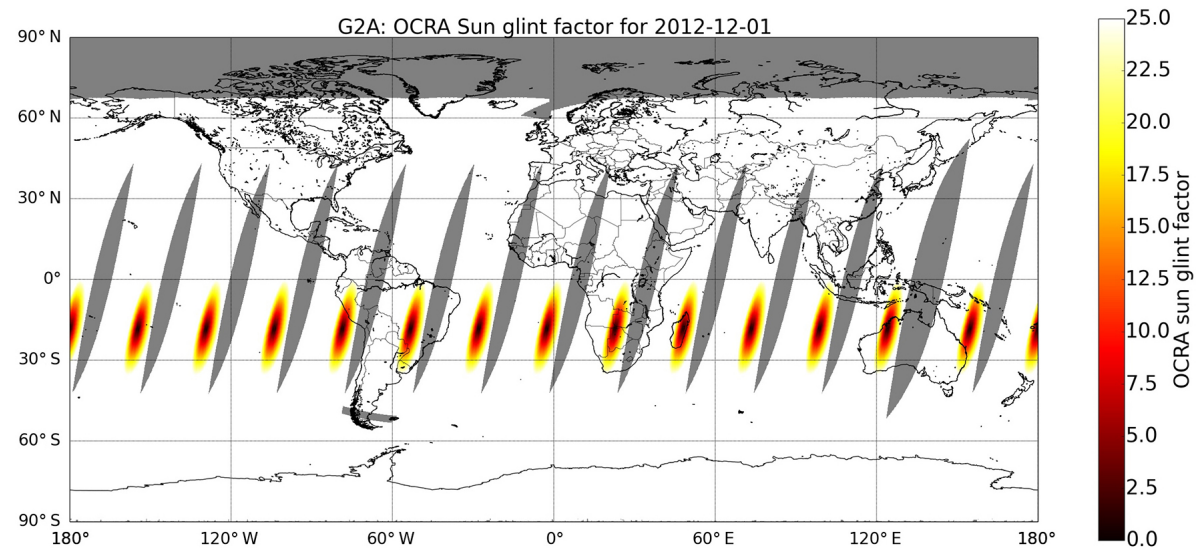

Figure 15. Sun glint factors for GOME-2A for 1 December 2012. If the sun glint factor is below 25 (i.e., nonwhite in the plot), a measurement over water may possibly be affected by sun glint.
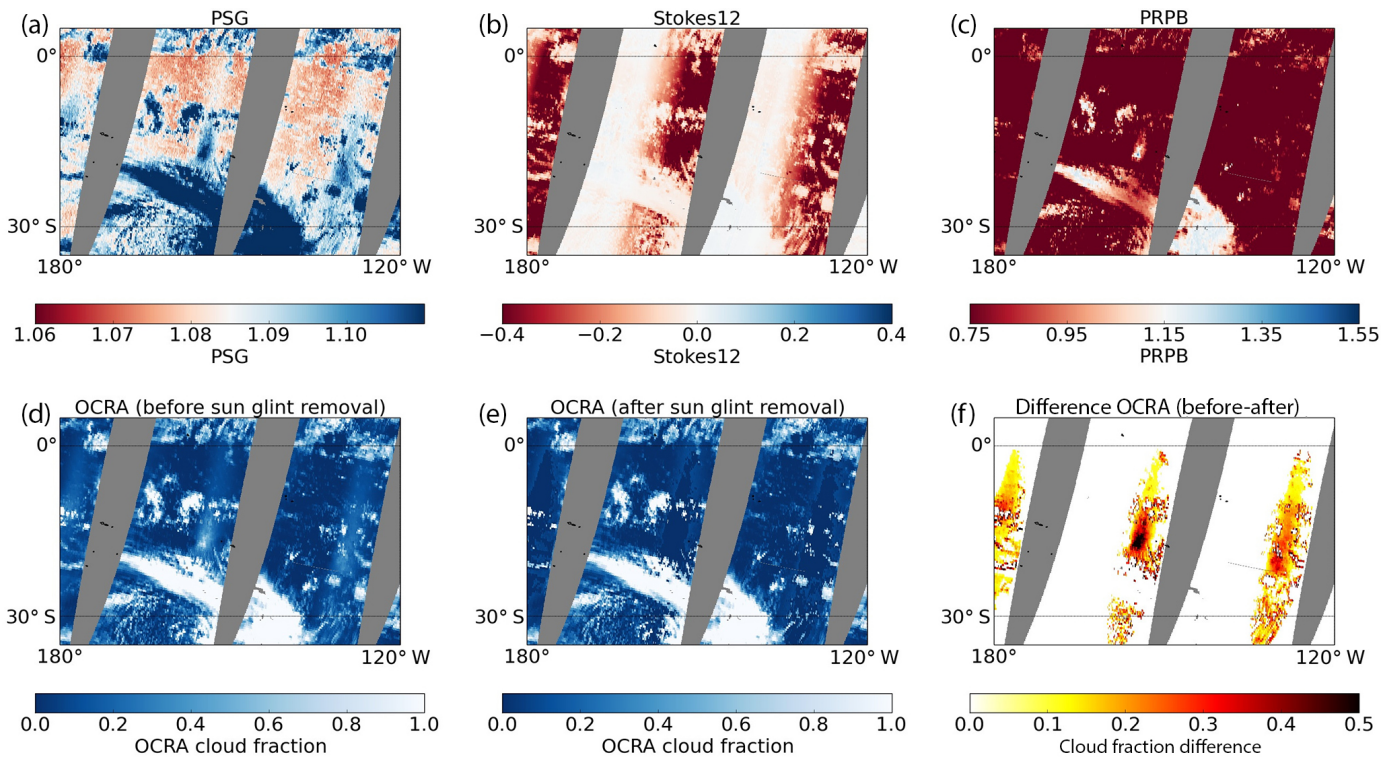

Figure 16. Example of the performance of the OCRA sun-glint removal scheme for GOME-2A data. A zoomed-in image of three orbits from 1 December 2012 in the region is shown, covering roughly 120 to $180^{\circ}$ west and 0 to $30^{\circ} \mathrm{S}$. Areas without coverage are shown in grey. Panels (a, b, c) show the properties PSG, Stokes12 and PRPB, respectively. PSG is the ratio of PMD4 to PMD3, Stokes12 represents the Stokes fraction of PMD12 and PRPB the ratio of the OCRA colors PR and PB. Panels (d, e, f) depict OCRA cloud fraction before sun glint removal, OCRA cloud fraction after sun glint removal and cloud-fraction difference after sun glint removal, respectively. See text for further details.

over water, which may possibly be affected by sun glint, is purely based on geometrical conditions. Due to the geometry of the MetOp-A/B orbits, sun glint for GOME-2 can only appear in the eastern part of the swath. Based on the solar zenith angle $\Theta_{\odot}$, satellite zenith angle $\Theta_{\text {sat }}$, solar azimuth angle $\varphi_{\odot}$ and satellite azimuth angle $\varphi_{\text {sat }}$, a sun glint factor $v$ is calculated:

$v=\sqrt{\left(\left|\Theta_{\odot}-\Theta_{\text {sat }}\right|-2\right)^{2}+\left(\varphi_{\text {sat }}-\varphi_{\odot}-180\right)^{2}}$.

OCRA raises a flag of possible sun glint if $v$ is below a certain threshold $v_{\text {thres }}$, which was determined empirically and set to 25 , and if the measurement is over water. For each orbit, this results in roughly ellipsoidal-shaped regions in the eastern part of the swath which have an extension of roughly $30^{\circ}$ in latitudinal and $10^{\circ}$ in longitudinal direction. The possibility for sun glint increases the closer the measurement is to the center of the ellipse. This is illustrated in Fig. 15. The latitudinal location of the ellipse depends on the season and reaches its highest latitudes in June/July, extending roughly from +60 to $+20^{\circ}$. The lowest latitudes are reached in December/January, extending roughly from 0 to $-40^{\circ}$. 


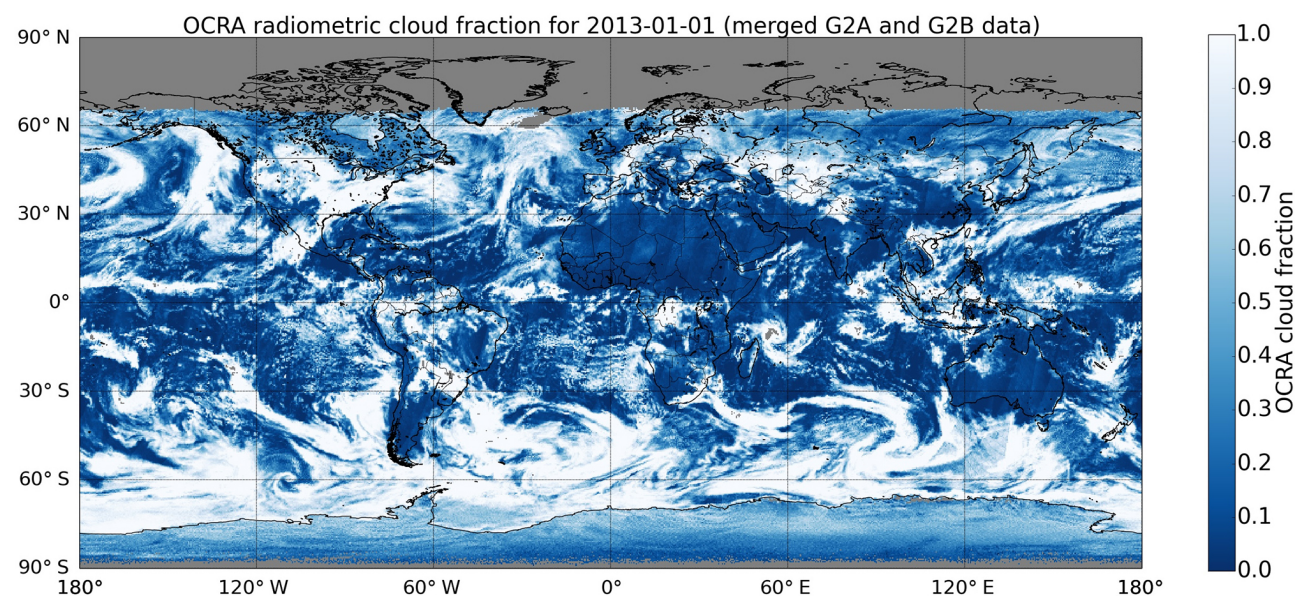

Figure 17. Global map with OCRA cloud fractions for 1 January 2013. The data from both sensors, GOME-2A and GOME-2B, have been merged in this plot in order to provide a daily, global cloud-fraction coverage without gaps between the swaths.

Based on Loyola et al. (2011) and in addition to flagging possible sun glint situations, we also improved the algorithm to find a correction for the affected scenes. To do so, we need to distinguish whether a retrieved cloud fraction is in fact due a cloud or if it is mimicked by sun glint (which can only appear in the absence of clouds under clear-sky conditions). For measurements, which may possibly be affected by sun glint and also are over water, the following steps are undertaken. First we consider a cloud-fraction threshold of 0.1 . Sun glint is only corrected above this threshold, meaning that we assume sun glint to cause cloud-fraction signals above 0.1 . Next, we introduce three quantities which are capable of distinguishing clouds from sun glint if they are used in concert. One is a reflectance ratio in the blue spectral part. We use the ratio of PMD4 to PMD3 (see Table 1). The second is the Stokes fraction (see Sect. 3.7 in Munro et al., 2016, for further information) in the red (PMD12) and the third is the ratio of the OCRA colors PR/PB (see Table 2). Let us call these three indicators PSG, Stokes12 and PRPB. PSG separates cloudy and sun glint scenes from clear scenes if the scene reflectance is above a certain threshold. The other two indicators distinguish clouds from sun glint. If the absolute value of Stokes 12 is below an empirically determined threshold, the signal will be due to clouds and cannot be due to sun glint. This is based on the assumption that clouds tend to be depolarizing, due to multiple scattering, and the Stokes fraction will therefore be close to zero for cloudy scenes. A detailed investigation of GOME-2 polarization spectra and the influence of clouds on the Stokes fraction is presented in Tilstra et al. (2014a). Finally, if the value of the third indicator PRPB is below an empirically determined threshold, the signal will be likely due to a cloud. Thus combining these three criteria, we are able to distinguish between cloud and sun glint, and hence correct for it (the cloud fraction is set to zero in this case). The three quantities used in our sun glint removal procedure are shown together with the cloud frac- tions before and after sun glint removal for a test scene in Fig. 16. Note that the bright ellipsoidal sun glint signals are successfully removed in panel e without affecting the true cloud signals. The empirical thresholds are given below.

- PSG $=1.050$, abs $($ Stokes 12$)=0.125, \mathrm{PRPB}=1.15$ for GOME-2A data before 11 March 2008 (i.e., valid for PMD Def. 1.0),

- PSG $=1.080, \operatorname{abs}($ Stokes 12$)=0.125, \mathrm{PRPB}=1.15$ for GOME-2A data after 11 March 2008 (i.e., valid for PMD Def. 3.1),

- $\mathrm{PSG}=0.995$, abs $($ Stokes 12$)=0.100, \mathrm{PRPB}=1.00$ for GOME-2B data.

Subplot $\mathrm{f}$ basically shows which measurements inside the ellipse defined by the geometrical conditions are affected by sun glint and the color scale gives a measure for the strength of the sun glint, i.e., virtual cloud fraction caused by sun glint. Note that the enhanced reflectance due to sun glint may mimic a large virtual cloud fraction in small localized regions (e.g., the bright feature seen at $15^{\circ} \mathrm{S}$ and $155^{\circ} \mathrm{W}$ ) whereas the smoother part spread over the whole sun glint area causes virtual cloud fractions pronounced in the range around 0.1 to 0.3 . A flag is set for each measurement where a sun glint correction was applied (all pixels with a cloudfraction difference larger than 0.1 in panel $f$ of Fig. 16). For all quantities involved, we use the corrected reflectances as outlined in Sect. 2.2.

A similar approach to investigating sun glint in GOME-2 data has already been presented by Loyola et al. (2011) and Beirle et al. (2013).

An example for a full day of OCRA cloud fractions after sun glint filtering, based on GOME-2A and GOME-2B data merged together, is shown in Fig. 17. 

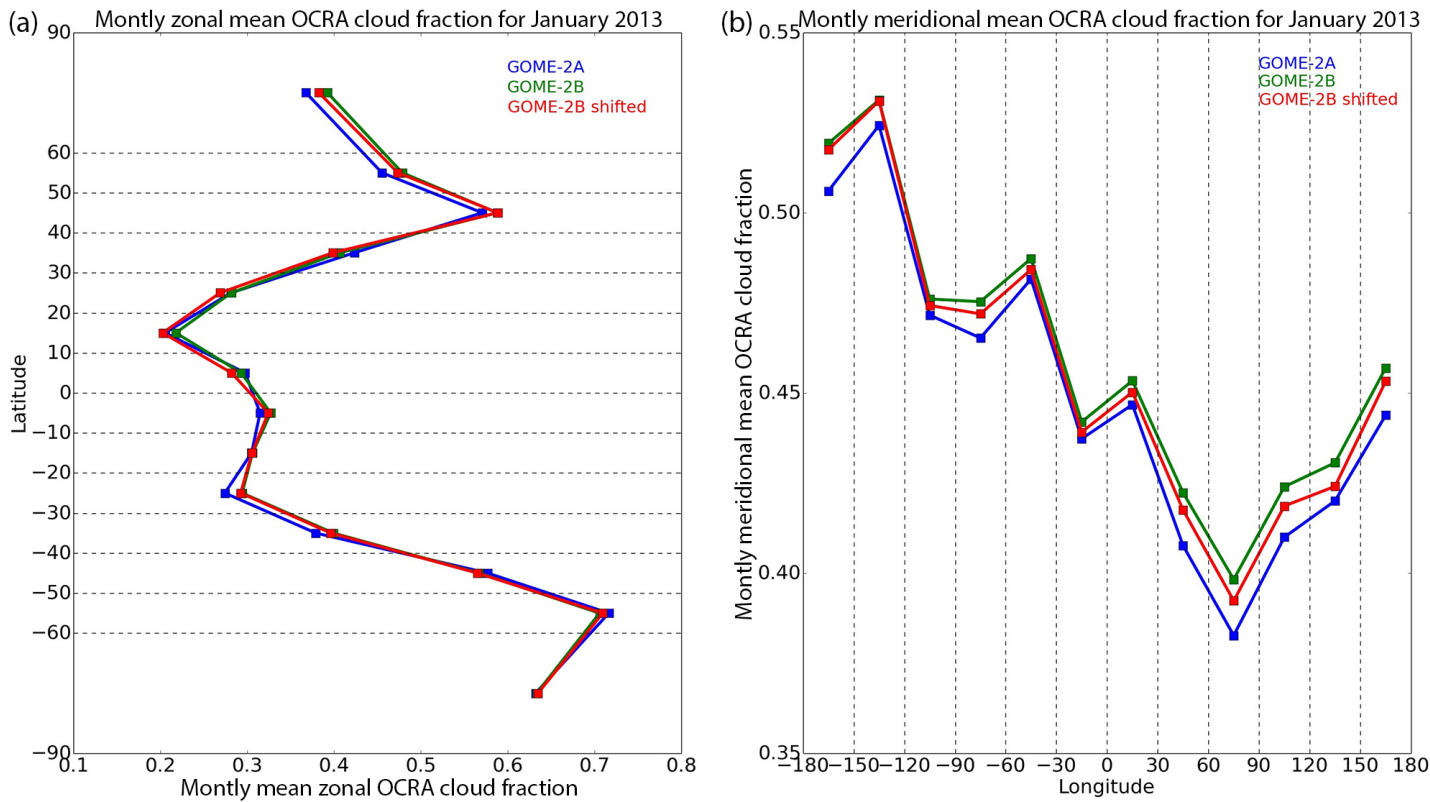

Figure 18. Monthly (a) zonal and (b) meridional OCRA cloud fractions from GOME-2A and GOME-2B based on all data from the month of January 2013, i.e., where both instruments operated in the full $1920 \mathrm{~km}$ nominal swath mode.

\section{Results}

The following subsections present the results of several comparison studies. The OCRA cloud fractions are intercompared for both sensors, GOME-2A and GOME-2B, as well as for both polarization cases. Furthermore, comparisons of the OCRA cloud fractions to those of AVHRR and FRESCO have been carried out.

\subsection{Comparison of OCRA cloud fractions from GOME-2A and GOME-2B}

For one full month of data, January 2013, the OCRA cloud fractions based on GOME-2A data are compared to those based on GOME-2B data. This time frame was chosen because both instruments operated in full swath mode at that time; hence, the most similar geographic coverage possible is established. Figure 18 shows the monthly mean cloud fractions for GOME-2A and GOME-2B, subdivided into 10-degree wide zonal bins (subplot a) and 30-degree wide meridional bins (subplot $b$ ). Three data sets are used to generate this figure: OCRA cloud fractions based on GOME-2A reflectances (blue data points), OCRA cloud fractions based on GOME-2B reflectances (green data points) and OCRA cloud fractions based on shifted GOME-2B reflectance data (red data points). The shifted GOME-2B reflectance data have been generated in order to homogenize with GOME$2 \mathrm{~A}$ reflectances. The shift was determined in the following way: for 30 full days of data spread over a 60-day time range, the offset between the mean global reflectance in the latitude range from $60^{\circ} \mathrm{S}$ to $60^{\circ} \mathrm{N}$ has been determined separately for GOME-2A and GOME-2B for all three OCRA colors. The GOME-2B reflectances, used to retrieve the green data points, have then been shifted by the mean offset in order to generate the homogenized GOME-2B reflectances used to retrieve the red data points. Figure 19 shows the correlation of the cloud-fraction data mentioned above for the cases based on original GOME-2B reflectances ( $y$ axis in panel a) and homogenized GOME-2B reflectances ( $y$ axis in panel $b$ ). It should also be noted here that a direct PMD pixel to PMD pixel comparison between GOME-2A and GOME-2B is not possible since the ground tracks are not the same and the temporal coverage is not the same. The former makes it necessary to regrid the data on a common grid before comparison and the latter is a nonavoidable error source since clouds may have moved during that time. Both effects together may pose a significant error source.

\subsection{Comparison of OCRA cloud fractions for $P$ - and S-polarization}

Most plots in the previous sections are only shown for reflectances based on the P-pol PMD data. Only in the final cloud-fraction map, Fig. 17, the mean of the P-pol-based and S-pol-based data are used. Larger discrepancies between the two polarization states do appear for instrumental degradation and scan-angle dependencies. Since these effects are corrected during the reflectance normalization, the discrepancies do not translate to the cloud-fraction determination. Hence, the cloud fractions based on using only P-pol PMD data do not significantly differ from those based on S-pol PMD data (this is evident in Fig. 20, which states a correlation coef- 

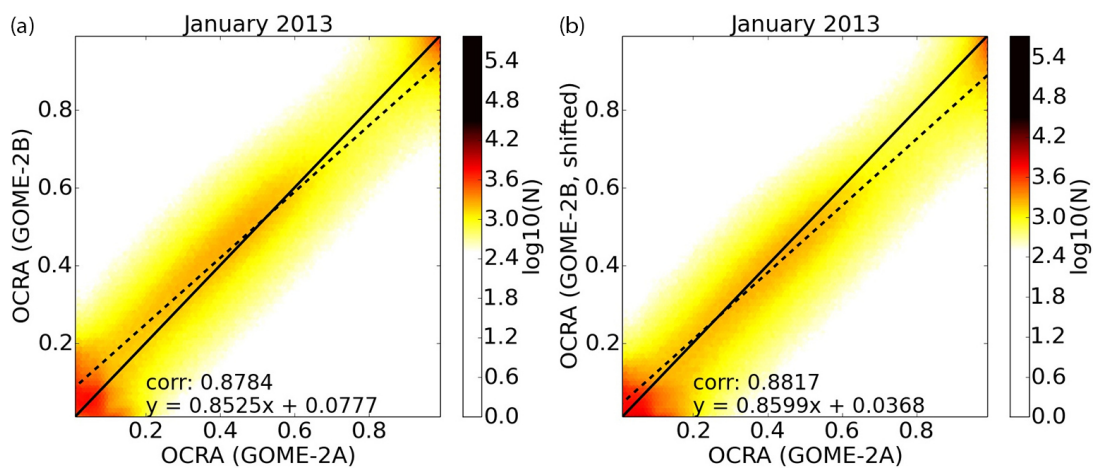

Figure 19. OCRA cloud fractions based on GOME-2A data vs. those based on GOME-2B data for all measurements within January 2013. Panel (a) is for the original GOME-2B reflectances and (b) is based on the homogenized GOME-2B reflectances, which have been adjusted to the GOME-2A reflectances.

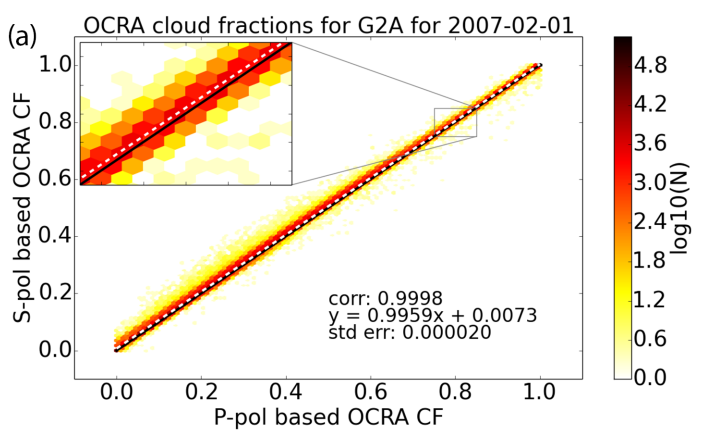

(b)

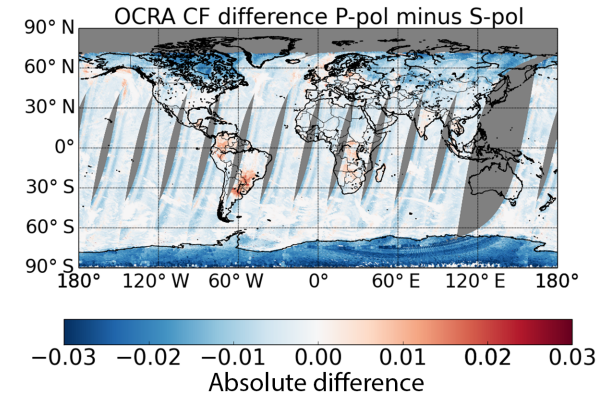

Figure 20. Comparison of P-pol-based OCRA cloud fractions to S-pol-based OCRA cloud fractions for GOME-2A for 1 February 2007. The correlation plot in (a) shows a very high agreement with a correlation coefficient of 0.9998 . The solid black line is the $1: 1$ line and the dashed white line is a fit with the parameters indicated in the plot. The absolute cloud-fraction differences are plotted on a world map in (b).

ficient $R=0.9998$ and a standard error of 0.00002 for the linear fit). The same holds true for the cloud-free maps, because these are also generated based on those reflectances which are corrected for instrumental degradation and scanangle dependencies.

\subsection{Comparison with AVHRR data}

We compared 12 days of OCRA data from GOME-2A/B with data from the AVHRR (advanced very high resolution radiometer) instrument, which is mounted on the same platform as the GOME-2 instruments, i.e., on MetOp-A and MetOp-B. AVHRR is an across-track scanner sensing the radiation backscattered from Earth in six channels from the visible/near-infrared range towards the thermal infrared. The spatial resolution is $1 \mathrm{~km}$ at nadir. Based on the dedicated cloud-test results provided with the AVHRR level-1B files, the geometrical cloud fraction for one GOME-2 PMD pixel is derived as the fraction of the sum of all cloudy pixels to the total number of AVHRR pixels collocated within one GOME-2 PMD pixel. This AVHHR cloud fraction is then added as an extra field to the GOME-2 level-1B file. In early 2014, R. Lang (EUMETSAT) provided 12 test days of collocated AVHRR geometrical cloud fractions to GOME-2 PMD pixels. These comprise the first day of each month between December 2012 and November 2013. Here we compare the GOME-2A OCRA radiometric cloud fractions for 1 December 2012 with the collocated AVHRR geometrical cloud fractions. Figure 21 shows the OCRA (panel a) and AVHRR (panel c) cloud fractions for MetOp-A on a world map. The absolute differences are plotted in panel b) and a correlation map is found in panel d). The overall largescale cloud structures are very similar in both products. Although the linear correlation is relatively high (linear correlation coefficient of $R=0.88$, see bottom right panel), differences appear as a systematic offset towards larger AVHRR cloud fractions of roughly 0.16 . This may be explained by the fact that UVN radiances from GOME-2 are less sensitive to clouds with low optical thickness (e.g., cirrus clouds) compared to NIR or thermal infrared radiances from AVHRR. In Fig. 22, histograms of the cloud fractions based on OCRA and AVHRR are plotted in panel a. Panel b shows a histogram of the cloud-fraction differences between OCRA and AVHRR for the same day (1 December 2012). The histogram 


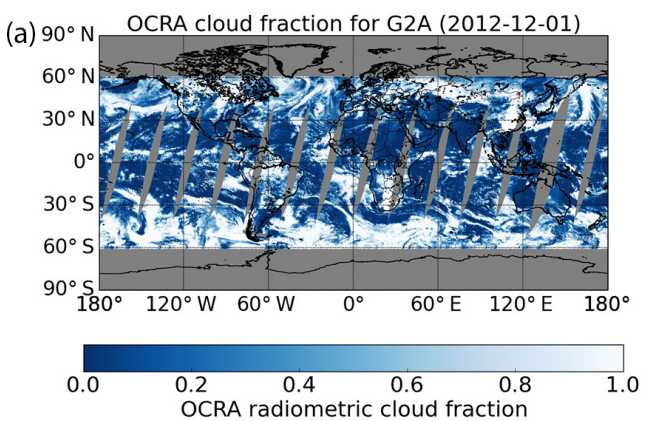

(c) $90^{\circ} \mathrm{N}$ AVHRR cloud fraction for G2A (2012-12-01)

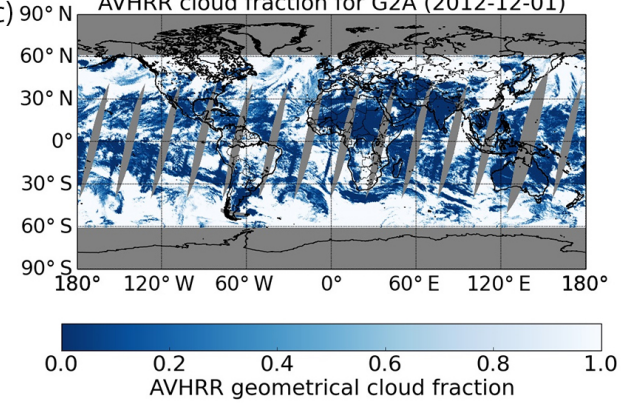

(b) $90^{\circ} \mathrm{N}$ Cloud fraction difference OCRA-AVHRR
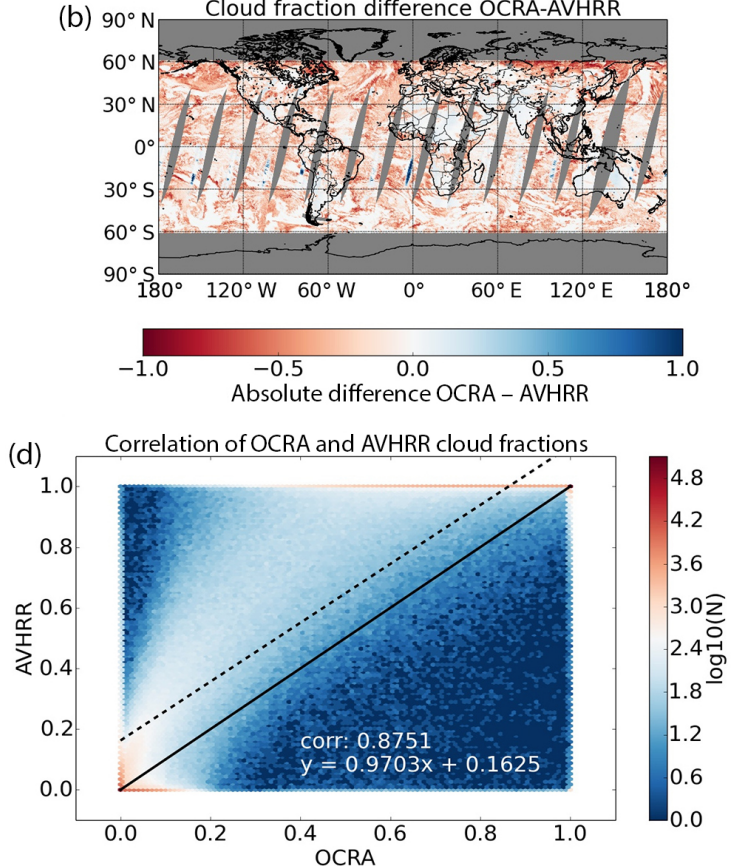

Figure 21. Comparison of GOME-2A OCRA cloud fractions (a) with colocated AVHRR cloud fractions (c) for 1 December 2012. The absolute differences are plotted in (b) while subplot (d) shows the correlation. The solid black line is the $1: 1$ identity and the dashed line represents a linear fit with the parameters specified in the plot.
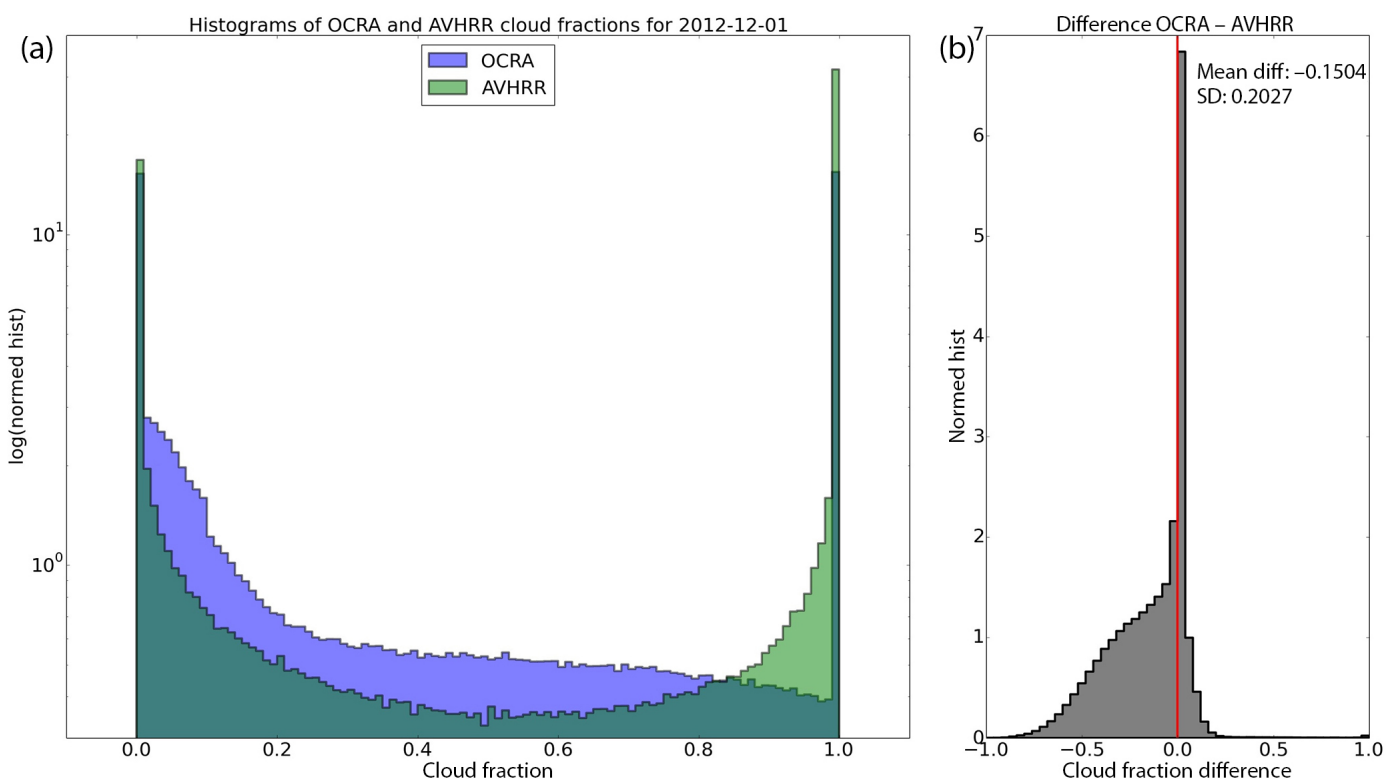

Figure 22. Histograms of OCRA and AVHRR cloud fractions for MetOp-A on 1 December 2012 are shown in (a), while a histogram of the cloud-fraction differences is plotted in (b).

of the cloud-fraction differences has a mean and a standard deviation of -0.15 and 0.20 , respectively, and looks very similar to the histogram shown in the right panel of Fig. 4 in Loyola et al. (2007). The latter compares OCRA cloud fractions derived from the GOME (Global Ozone Monitoring
Experiment) instrument on ERS-2 (European Remote Sensing 2 Satellite) and the SEVIRI (Spinning Enhanced Visible and Infrared Imager) instrument on MSG (METEOSAT Second Generation) and finds a mean difference of -0.21 with a standard deviation of 0.26 . Since GOME is not sensitive 

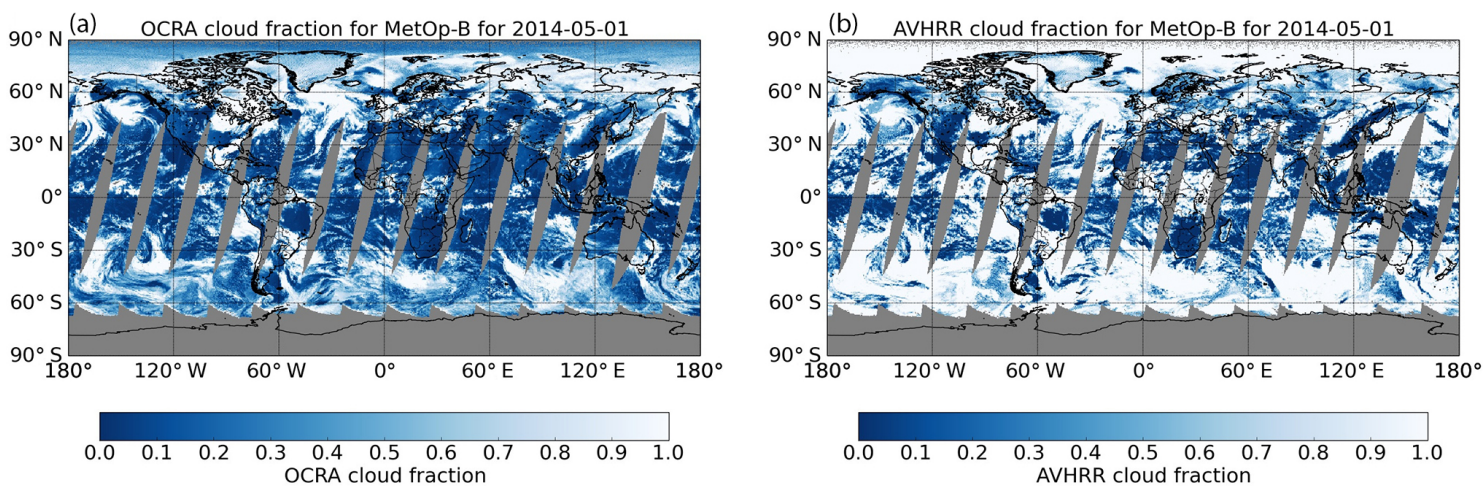

Figure 23. Comparison of OCRA (a) and AVHRR (b) cloud fractions for MetOp-B on 1 May 2014. The colocated AVHRR data for the GOME-2 PMD footprints were taken from the PMAp product (see text for further details).
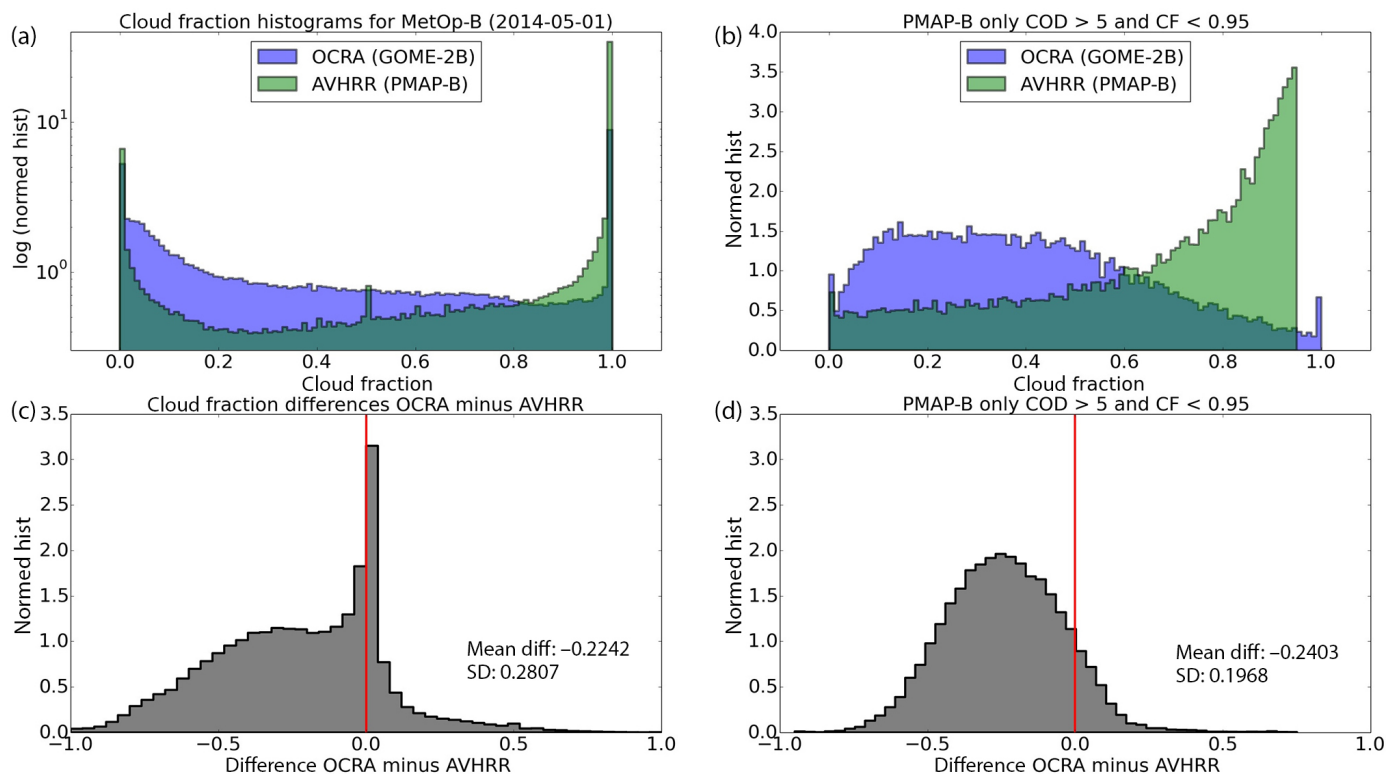

Figure 24. Panels (a, b) show a comparison of OCRA (blue) and AVHRR (green) cloud-fraction histograms for MetOp-B on 1 May 2014. Panels (c, d) show histograms of the cloud-fraction difference OCRA minus AVHRR. All PMAp measurements are included in (a, c) but only PMAp measurements with a COD larger than 5 and CF smaller than 0.95 are considered in (b, d).

to optically thin clouds, but SEVIRI is, the situation is very similar to the comparison of the GOME-2/AVHRR pair. One possibility for circumventing these different cloud sensitivities and achieving a better agreement is to filter the clouds with low optical thickness (below a certain threshold) from the AVHRR or SEVIRI data. For the latter case this has been done in the left panel of Fig. 4 by Loyola et al. (2007) and results in a much better agreement of the GOME and SEVIRI data. Concerning GOME-2 and AVHRR, a similar cloud optical thickness filtering of the AVHRR data is outlined in the following subsection.

\subsubsection{Cloud optical thickness filter}

Since May 2014, EUMETSAT provides the AVHRR cloud fraction colocated to the GOME-2 PMD footprints as an operational (but not yet validated) product. This EUMETSAT polar multi-sensor aerosol product (PMAp) provides the cloud optical depth (COD) in addition to the cloud fraction (EUMETSAT, 2015).

A comparison of the OCRA cloud fractions with the AVHRR cloud fractions taken from this PMAp product is shown in Fig. 23 for data from 1 May 2014. Both data sets are matched to a common lat/lon grid of $0.4^{\circ}$ resolution. As before, the general large-scale cloud structures agree very well. To account for GOME-2 insensitivity to low optical thickness clouds, we filtered out all AVHRR cloud-fraction 


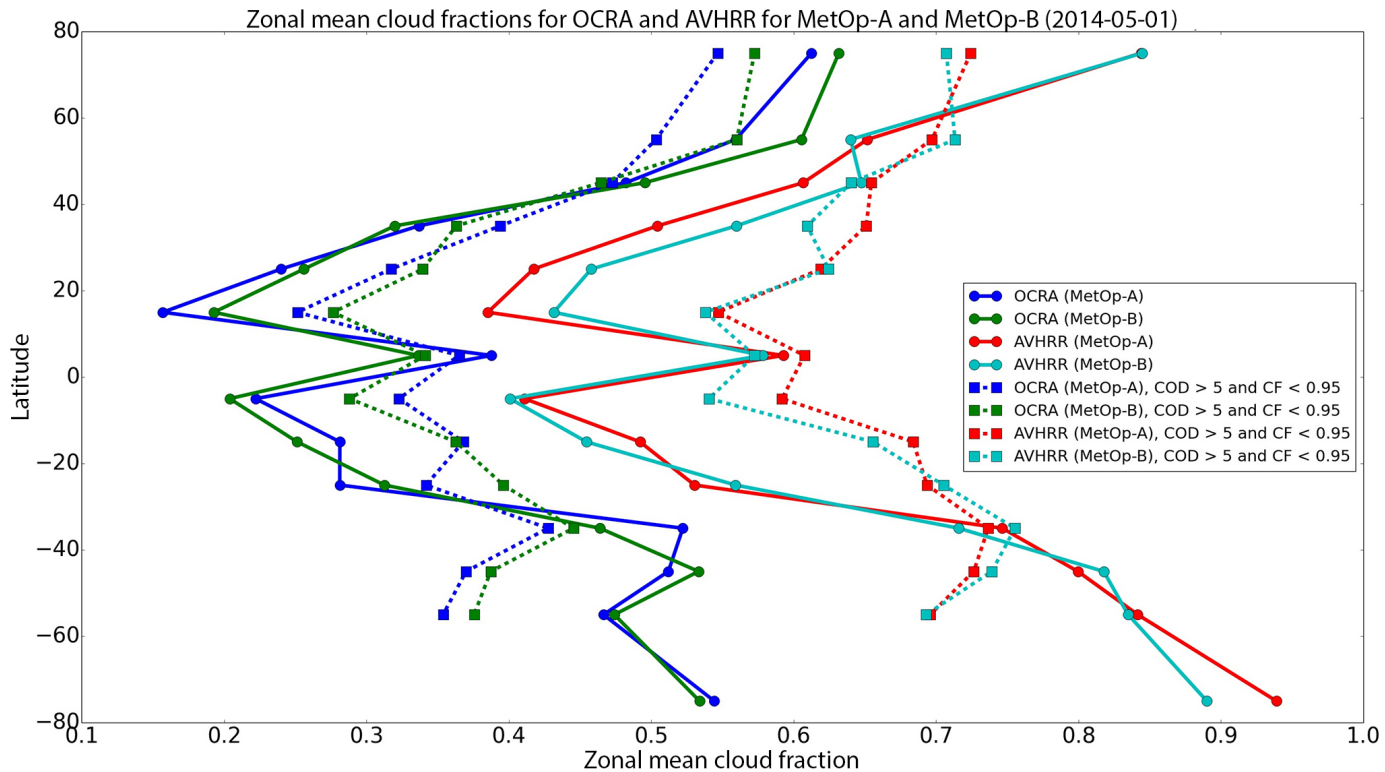

Figure 25. Zonal mean cloud fractions for 1 May 2014 for MetOp-A and MetOp-B based on OCRA and AVHRR cloud fractions. The solid lines represent the unfiltered data while the dashed lines represent the data after filtering out cloud fractions with a COD smaller than 5 and a CF larger than 0.95 .
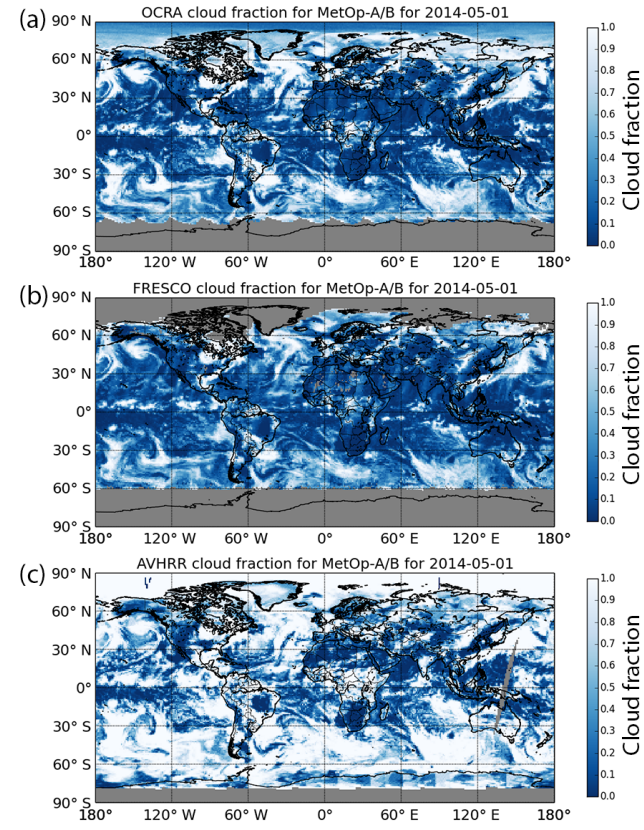

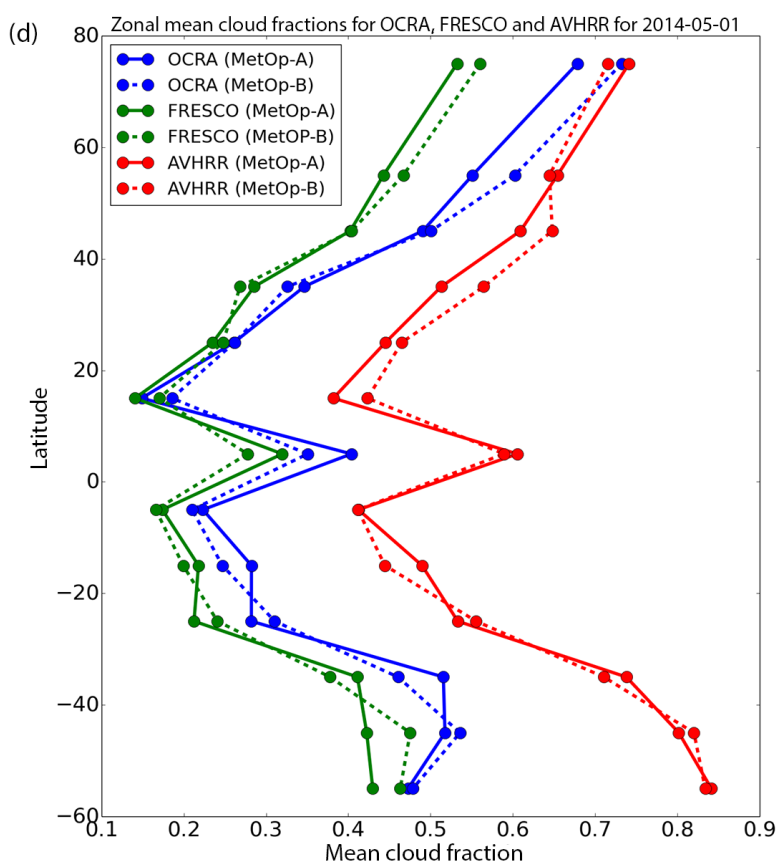

Figure 26. Intercomparison of OCRA radiometric, FRESCO effective and AVHRR geometric cloud fractions gridded to a common spatial grid of 1-degree in latitude and longitude. The data are from 1 May 2014. Panels (a, b, c) show the OCRA, FRESCO and AVHRR cloud fractions, respectively. In all cases the data from both MetOp-A and MetOp-B have been merged. For grid cells containing multiple measurements, the resulting cloud fraction is an average. Panel (d) illustrates zonal mean cloud fractions separately for MetOp-A and MetOp-B. Note that for $(\mathbf{d})$ only those grid cells from $(\mathbf{a}, \mathbf{b}, \mathbf{c})$, which contain valid values for all three cases (OCRA and FRESCO and AVHRR), are used. The latitude bands have a width of 10 degrees. 


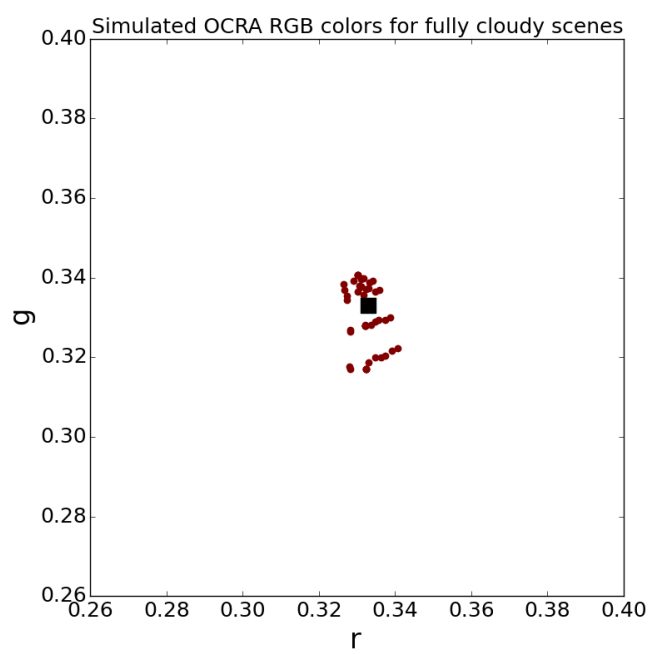

Figure 27. Simulated OCRA RGB colors in a normalized rg-color diagram. The theoretical white point at $(1 / 3,1 / 3)$ is shown as a black square and the red dots represent fully cloudy scenes for various cloud types and observation geometries. See text for further details on the simulations.

measurements which have a COD smaller than 5. Additionally, all cloud fractions larger than 0.95 are rejected in order to avoid ambiguities due to different treatments of the cloud fraction over snow/ice scenes where the AVHRR cloud fraction is set to 1 . The effect of this treatment is visible in Fig. 24. Note that in panel a there are many $\mathrm{CF}=1$ cases for AVHRR which are considerably less for OCRA. The major contribution to these large deviations comes from polar regions (this is also obvious in Fig. 23). In the histograms of the cloud fractions (panels a and b) and histograms of the cloud-fraction differences (panels $\mathrm{c}$ and $\mathrm{d}$ ) visualized in Fig. 24 it is noted that the COD and CF filtering is able to remove the strong asymmetry seen in panel c), but the rather large systematic offset $(-0.24$ in this case) still remains in panel d). Finally, Fig. 25 nicely illustrates that this systematic offset between the radiometric (GOME-2) and the geometric (AVHRR) zonal mean cloud fractions has the same sign over the whole latitude range. For all latitude bands considered, the AVHRR cloud fraction is larger than the OCRA cloud fraction.

\subsection{Comparison with L1 FRESCO data}

Since the GOME-2 level 1 data also contain the effective cloud fraction based on the FRESCO algorithm, Fig. 26 shows an intercomparison of OCRA, FRESCO and AVHRR cloud fractions, both for MetOp-A and MetOp-B, on 1 May 2014. The OCRA and AVHRR data are given for the $10 \mathrm{~km} \times 40 \mathrm{~km}$ PMD footprint resolution, whereas the FRESCO data are given in the nominal $80 \mathrm{~km} \times 40 \mathrm{~km}$ ground pixel resolution. For the maps shown in panels a, b and c of Fig. 26, all data have therefore been regridded to a common spatial grid of one degree resolution in latitude and longitude. Subplot d of Fig. 26 illustrates the zonal mean cloud fractions for the same data, but separately for MetOpA and MetOp-B.

\section{Discussion}

A known issue for cloud-fraction retrieval algorithms in the UVN wavelength range is the performance over very bright surfaces like snow or ice. In such cases, external databases of daily snow/ice cover are often incorporated, the affected scenes are flagged, given an arbitrary cloud-fraction value (e.g., 1) and an effective scene albedo is retrieved instead. In OCRA, the cloud fraction is calculated regardless of the surface condition. For the snow/ice scenes mentioned above, this requires the cloud-free background maps to be as close as possible to the current surface situation in order to represent the cloud fraction over snow/ice as realistically as possible. As mentioned before, the cloud-free reflectances for the OCRA RGB colors for a particular grid cell are interpolated towards a daily value in between two monthly cloud-free maps. If we imagine that the cloud-free reflectance of a particular grid cell represents a snow/ice situation (i.e., higher background) and in the same cell the snow/ice is melted in the next month (i.e., lower background), OCRA's linear interpolation scheme may introduce some uncertainties since snow/ice melting and particularly new snow/ice coverage may happen on shorter timescales than 30 days. If melting or new snow occurs within the timescale of days, it would of course be better to have e.g., weekly cloud-free maps, but for this, there are simply not enough data available. Hence, monthly maps with linear interpolation was found to be a reasonable trade-off that can be done given the current combination of time base, grid cell size and PMD pixel size. The effect of melting seasons and fresh snow coverage on the cloud-free background was shown in Fig. 12. In this figure, it can also be seen that even for snow/ice surfaces the cloudfree background does not coincide with the white point of the rg-diagram, which is why OCRA can also retrieve the cloud fraction for these cases instead of setting an arbitrary value. However, OCRA may slightly underestimate the cloud fraction in these cases due to the fact that the scaling factor $\alpha$ is optimized for all possible surface conditions and not for snow/ice conditions alone. From the operational point of view it is desirable to have as few input parameters to OCRA as possible (e.g., only one set of scaling factors for all surface conditions), but in this case separate scaling factors for the different surface types (e.g., permanent ice, sea ice, snow, desert, water, land) are considered to be included in a future update to the OCRA algorithm.

An alternative to choosing the maximum distance in the rg-diagram as in the cloud-free situation would be to do a histogram analysis of $\rho\left(\lambda_{i}\right)-\rho_{\mathrm{CF}}\left(\lambda_{i}\right)$ for each individual grid cell. This would work fine for gaussian distributions (grid 

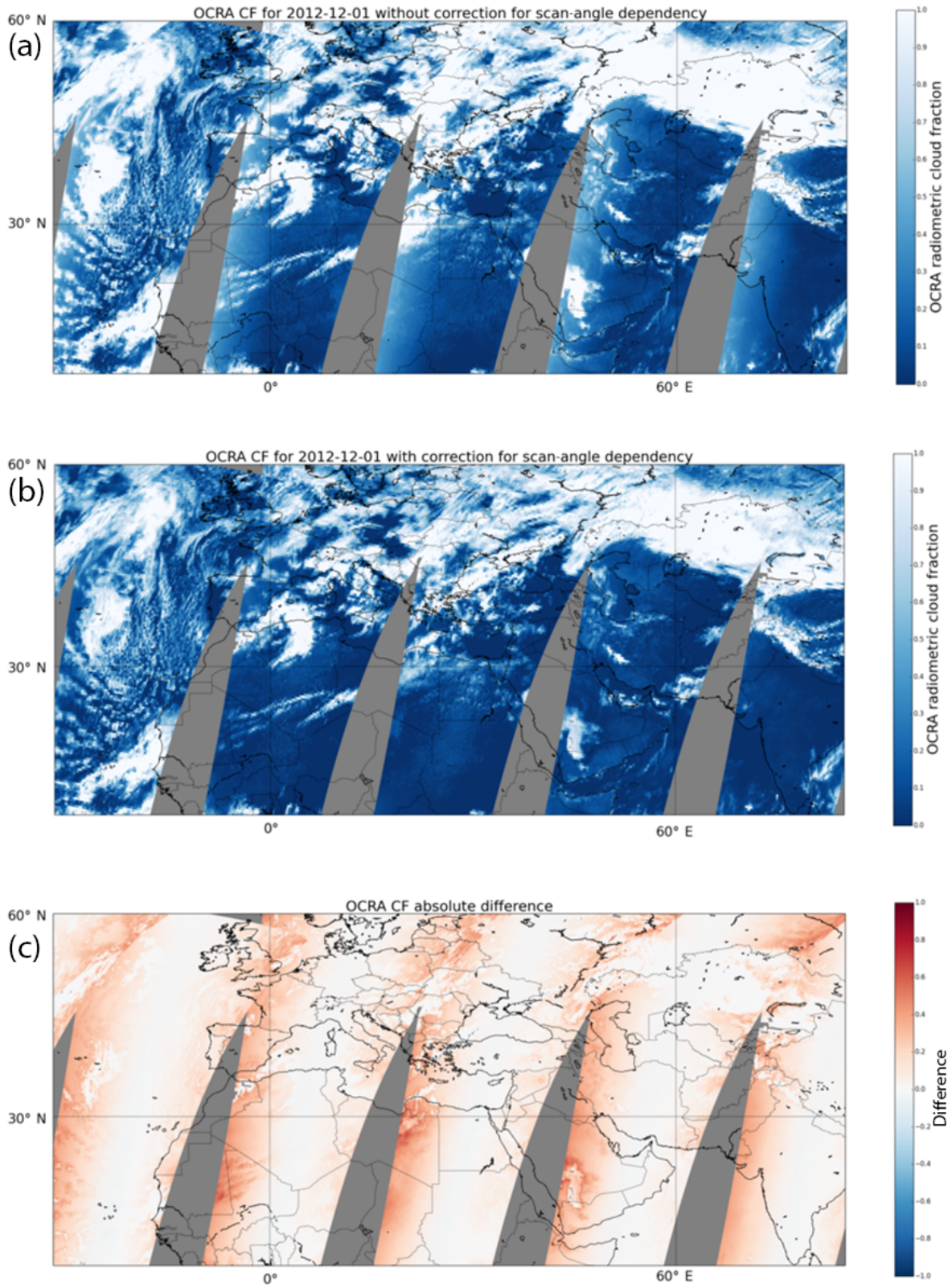

Figure 28. OCRA radiometric cloud fractions for GOME-2A for 1 December 2012 based on reflectances (a) without corrections for viewing angle dependencies and (b) with corrections for viewing angle dependencies as outlined in Sect. 2.2.2. Subplot (c) shows the absolute difference of the cloud fractions in $(\mathbf{a}, \mathbf{b})$. In the example shown here, the effect of the correction is particularly prominent in the western part of the swaths.

cells without strong surface condition variations) but would also cause problems if the distribution is bimodal or multimodal (grid cells with seasonal changes of the surface conditions).

Further attempts have been undertaken in order to distinguish snow/ice from clouds. It was noticed that the difference between the P-pol-based OCRA cloud fraction and the S-polbased OCRA cloud fraction depends slightly on the underlying surface. As can be seen in panel b of Fig. 20, the cloudfraction difference of the P-pol-based cloud fraction minus the S-pol-based cloud fraction seems to be particularly negative (blue in the plot) over snow/ice covered surfaces, e.g., Antarctica, Hudson Bay, Greenland, Siberia. Being an interesting aspect, this approach to identifying snow/ice via the cloud fractions based on different polarization states may be pursued further in future work.

Figure 27 presents simulated OCRA RGB colors plotted in a normalized rg-color diagram for a set of fully cloudy scenes. In the simulations, which have been performed with libRadtran (Mayer and Kylling, 2005) for a grass surface, 
various cloud optical thicknesses $(10,15,30,50)$ have been considered for a solar zenith angle of $30^{\circ}$, viewing zenith angles of $0,25.8$ and $36.9^{\circ}$ and relative azimuth angles of $0,30,60$ and $90^{\circ}$. Figure 27 clearly shows that the fully cloudy scenes slightly scatter around the theoretical white point value. This behavior is also seen in the normalized rgcolor diagram based on the measured data in Fig. 14, where the cloudy scenes also slightly deviate from the theoretical $(1 / 3,1 / 3)$ location.

Finally, the effect of correcting the reflectances for scan angle dependencies is illustrated in Fig. 28 and the improvement in subplot b compared to subplot a clearly demonstrates the necessity of performing the corrections outlined in Sect. 2.2.2.

\section{Conclusions}

We have presented version 3.0 of the OCRA cloud-fraction algorithm applied to data measured with the GOME-2 instrument onboard the MetOp satellites. Improvements with regard to the previous OCRA version include a degradation correction of the PMD reflectances as well as corrections for scan angle and latitudinal dependencies. In addition, the cloud-free composite maps are now based on more than six years of GOME-2A data. An improved sun glint flagging and removal has been implemented, which now also considers the Stokes fraction and an additional color ratio in order to distinguish between sun glint and real clouds.

The PMD-based OCRA cloud fractions have been compared to collocated AVHRR cloud fractions and show a good general agreement. However, a systematic offset is attributed to different sensitivities to low optical thickness clouds due to the different spectral ranges covered by the GOME- 2 and AVHRR instruments.

In addition to the simple OCRA color space approach, which does not need expensive radiative transfer modeling, another advantage of OCRA lies in its very fast computational performance. This is especially relevant for providing products in near real time. All external input, like the cloudfree reflectance composite maps, are precalculated look-up tables (LUTs) and do not need to be calculated online. The radiometric cloud fractions for a full GOME-2 orbit with around 120000 single PMD measurements are calculated in only $\approx 20 \mathrm{~s}$ (operational). The OCRA algorithm was used for the generation of operational products from GOME and SCIAMACHY and is not limited to PMD data, but can also be used with normal radiance data (e.g., OMI, TROPOMI). At the beginning of a new mission, cloud-free reflectance composites from a predecessor mission can be used as an initial input. As soon as a sufficient amount of data is collected to minimize residual cloud contamination, the cloudfree reflectance composite maps will be based on the same instrument.
Acknowledgements. The authors would like to thank Rüdiger Lang (EUMETSAT) for providing the AVHRR test data colocated to the GOME-2 PMD footprints. The PMAp data used in this work have been acquired using the EUMETSAT Earth Observation Portal https://eoportal.eumetsat.int/. Part of this work was related to the TROPOMI/S5P project and was supported by the Bavarian Ministry of Economic Affairs and Media, Energy and Technology grant 07 03/893 73/5/2013. Finally, the authors thank the anonymous reviewers for their fruitful inputs and suggestions which helped to improve this manuscript.

The article processing charges for this open-access publication were covered by a Research

Centre of the Helmholtz Association.

Edited by: A. Kokhanovsky

\section{References}

Beirle, S., de Vries, M., Lang, R., and Wagner, T.: An empirical Sun-glint index for GOME-2, 2013 Joint EUMETSAT/AMS Conference, available at: http://www.eumetsat.int/website/ $\mathrm{wcm} / \mathrm{idc} / \mathrm{idcplg}$ ?IdcService=GET_FILE\&dDocName=PDF_ CONF_P_S6_01_BEIRLE_P\&RevisionSelectionMethod= LatestReleased\&Rendition=Web (last access: 19 May 2016), 2013.

Bézy, J.-L., Sierk, B., Caron, J., Veihelmann, B., Martin, D., and Langen, J.: The Copernicus Sentinel-5 mission for operational atmospheric monitoring: status and developments, in: Sensors, Systems, and Next-Generation Satellites XVIII, Vol. 9241 of Proceedings of the SPIE, 92410H, doi:10.1117/12.2068177, 2014.

Burrows, J. P., Weber, M., Buchwitz, M., Rozanov, V., LadstätterWeißenmayer, A., Richter, A., Debeek, R., Hoogen, R., Bramstedt, K., Eichmann, K.-U., Eisinger, M., and Perner, D.: The Global Ozone Monitoring Experiment (GOME): Mission Concept and First Scientific Results, J. Atmos. Sci., 56, 151-175, 1999.

Casacchia, R., Salvatori, R., Cagnati, A., Valt, M., and Ghergo, S.: Field reflectance of snow/ice covers at Terra Nova Bay, Antarctica, International J. Remote Sens., 23, 4653-4667, doi:10.1080/01431160110113863, 2002.

Dobber, M. R., Dirksen, R. J., Levelt, P. F., van den Oord, G. H. J., Voors, R. H. M., Kleipool, Q., Jaross, G., Kowalewski, M., Hilsenrath, E., Leppelmeier, G. W., de Vries, J., Dierssen, W., and Rozemeijer, N. C.: Ozone Monitoring Instrument Calibration, IEEE T. Geosci. Remote Sens., 44, 1209-1238, 2006.

EUMETSAT: GOME-2 Factsheet, available at: http://www.eumetsat.int/website/wcm/idc/idcplg?

IdcService=GET_FILE\&dDocName $=$ PDF GOME_FACTSHEET\&RevisionSelectionMethod= LatestReleased\&Rendition=Web (last access: 19 May 2016), 2014.

EUMETSAT: PMAP Factsheet, available at: http://www.eumetsat.int/website/wcm/idc/idcplg? IdcService $=$ GET_FILE $\&$ dDocName $=$ PDF PMAP_FACTSHEET\&RevisionSelectionMethod= 
LatestReleased\&Rendition=Web (last access: 19 May 2016), 2015.

Grzegorski, M., Wenig, M., Platt, U., Stammes, P., Fournier, N., and Wagner, T.: The Heidelberg iterative cloud retrieval utilities (HICRU) and its application to GOME data, Atmos. Chem. Phys., 6, 4461-4476, doi:10.5194/acp-6-4461-2006, 2006.

$\mathrm{Hu}, \mathrm{C} .:$ An empirical approach to derive MODIS ocean color patterns under severe sun glint, Geophys. Res. Lett., 38, L01603, doi:10.1029/2010GL045422, 2011.

Kay, S., Hedley, J. D., and Lavender, S.: Sun Glint Correction of High and Low Spatial Resolution Images of Aquatic Scenes: a Review of Methods for Visible and Near-Infrared Wavelengths, Remote Sensing, 1, 697-730, 2009.

Kay, S., Hedley, J., and Lavender, S.: Sun glint estimation in marine satellite images: a comparison of results from calculation and radiative transfer modeling, Appl. Optics, 52, 5631-5639, doi:10.1364/AO.52.005631, 2013.

Kokhanovsky, A. A., Rozanov, V. V., Zege, E. P., Bovensmann, H., and Burrows, J. P.: A semianalytical cloud retrieval algorithm using backscattered radiation in $0.4-2.4 \mu \mathrm{m}$ spectral region, J. Geophys. Res.-Atmos., 108, AAC 4-1-AAC 4-19, doi:10.1029/2001JD001543, 2003.

Levelt, P. F., van den Oord, G. H. J., Dobber, M. R., Malkki, A., Visser, H., de Vries, J., Stammes, P., Lundell, J. O. V., and Saari, H.: The Ozone Monitoring Instrument, IEEE T. Geosci. Remote Sens., 44, 1093-1101, 2006.

Loyola, D.: A new cloud recognition algorithm for optical sensors, in: Geoscience and Remote Sensing Symposium Proceedings, IGARSS '98, 1998 IEEE International, Vol. 2, 572-574, 1998.

Loyola, D.: Automatic cloud analysis from polar-orbiting satellites using neural network and data fusion techniques, in: Geoscience and Remote Sensing Symposium, IGARSS '04, 2004 IEEE International, Vol. 4, 2530-2533, 2004.

Loyola, D., Thomas, W., Livschitz, Y., Ruppert, T., Albert, P., and Hollmann, R.: Cloud Properties Derived From GOME/ERS-2 Backscatter Data for Trace Gas Retrieval., IEEE T. Geosci. Remote Sens., 45, 2747-2758, 2007.

Loyola, D. G., Koukouli, M. E., Valks, P., Balis, D. S., Hao, N., Van Roozendael, M., Spurr, R. J. D., Zimmer, W., Kiemle, S., Lerot, C., and Lambert, J.-C.: The GOME-2 total column ozone product: Retrieval algorithm and groundbased validation, J. Geophys. Res.-Atmos., 116, D07302, doi:10.1029/2010JD014675, 2011.

Mayer, B. and Kylling, A.: Technical note: The libRadtran software package for radiative transfer calculations - description and examples of use, Atmos. Chem. Phys., 5, 1855-1877, doi:10.5194/acp-5-1855-2005, 2005.

Munro, R., Lang, R., Klaes, D., Poli, G., Retscher, C., Lindstrot, R., Huckle, R., Lacan, A., Grzegorski, M., Holdak, A., Kokhanovsky, A., Livschitz, J., and Eisinger, M.: The GOME2 instrument on the Metop series of satellites: instrument design, calibration, and level 1 data processing - an overview, Atmos. Meas. Tech., 9, 1279-1301, doi:10.5194/amt-9-1279-2016, 2016.
Schoeberl, M. R., Douglass, A. R., Hilsenrath, E., Bhartia, P. K., Beer, R., Waters, J. W., Gunson, M. R., Froidevaux, L., Gille, J. C., Barnett, J. J., Levelt, P. F., and de Cola, P.: Overview of the EOS Aura Mission, IEEE T. Geosci. Remote Sens., 44, 10661074, 2006.

Stark, H. R., Moller, H. L., Courreges-Lacoste, G. B., Koopman, R., Mezzasoma, S., and Veihelmann, B.: The Sentinel-4 Mission And Its Implementation, in: ESA Living Planet Symposium, Vol. 722 of ESA Special Publication, p. 139, 2013.

Steinmetz, F., Deschamps, P.-Y., and Ramon, D.: Atmospheric correction in presence of sun glint: application to MERIS, Opt. Express, 19, 9783-9800, doi:10.1364/OE.19.009783, 2011.

Tilstra, L. G., Tuinder, O. N. E., and Stammes, P.: A new method for in-flight degradation correction of GOME-2 Earth reflectance measurements, with application to the Absorbing Aerosol Index, Proceedings of the 2012 EUMETSAT Meteorological Satellite Conference, available at: http://www.temis.nl/ airpollution/absaai/doc/EUMETSAT2012_Tilstra_et_al.pdf (last access: 19 May 2016), 2012.

Tilstra, L. G., Lang, R., Munro, R., Aben, I., and Stammes, P.: Contiguous polarisation spectra of the Earth from 300 to $850 \mathrm{~nm}$ measured by GOME-2 onboard MetOp-A, Atmos. Meas. Tech., 7, 2047-2059, doi:10.5194/amt-7-2047-2014, 2014a.

Tilstra, L. G., Tuinder, O. N. E., and Stammes, P.: Algorithm Theoretical Basis Document GOME-2 surface LER product, available at: http://o3msaf.fmi.fi/docs/atbd/Algorithm_Theoretical_Basis_ Document_LER_Nov_2014.pdf (last access: 19 May 2016), 2014b.

Van Roozendael, M., Loyola, D., Spurr, R., Balis, D., Lambert, J.-C., Livschitz, Y., Valks, P., Ruppert, T., Kenter, P., Fayt, C., and Zehner, C.: Ten years of GOME/ERS-2 total ozone data - The new GOME data processor (GDP) version 4: 1. Algorithm description, J. Geophys. Res.-Atmos., 111, D14311, doi:10.1029/2005JD006375, 2006.

Veefkind, J., Aben, I., McMullan, K., Förster, H., de Vries, J., Otter, G., Claas, J., Eskes, H., de Haan, J., Kleipool, Q., van Weele, M., Hasekamp, O., Hoogeveen, R., Landgraf, J., Snel, R., Tol, P., Ingmann, P., Voors, R., Kruizinga, B., Vink, R., Visser, H., and Levelt, P.: $\{$ TROPOMI $\}$ on the $\{$ ESA $\}$ Sentinel-5 Precursor: A $\{$ GMES $\}$ mission for global observations of the atmospheric composition for climate, air quality and ozone layer applications, Remote Sens. Environ., 120, 70-83, 2012.

Wang, P., Stammes, P., van der A, R., Pinardi, G., and van Roozendael, M.: FRESCO+: an improved $\mathrm{O}_{2}$ A-band cloud retrieval algorithm for tropospheric trace gas retrievals, Atmos. Chem. Phys., 8, 6565-6576, doi:10.5194/acp-8-6565-2008, 2008.

Zhang, H. and Wang, M.: Evaluation of sun glint models using \{MODIS \} measurements, J. Quant. Spectrosc. Ra., 111, 492506, doi:10.1016/j.jqsrt.2009.10.001, 2010. 